\title{
The natural gas supply chain: the importance of methane and carbon dioxide emissions
}

\author{
Paul Balcombe $^{a *}$, Kris Anderson $^{\mathrm{a}}$, Jamie Speirs ${ }^{\mathrm{b}}$, Nigel Brandon ${ }^{\mathrm{a}}$, Adam Hawkes ${ }^{\mathrm{a}}$ \\ a Sustainable Gas Institute, Imperial College London, 11 Prince's Gardens, London, SW7 1NA, UK \\ b Centre for Environmental Policy, Imperial College London, 13 Prince's Gardens, London, SW7 1NA UK \\ * Corresponding Author: p.balcombe@imperial.ac.uk
}

Keywords: Natural gas supply chain; methane emissions; fugitive leaks and vents.

\section{Abstract}

Natural gas is typically considered to be the cleaner-burning fossil fuel that could play an important role within a restricted carbon budget. Whilst natural gas emits less $\mathrm{CO}_{2}$ when burned than other fossil fuels, its main constituent is methane, which has a much stronger climate forcing impact than $\mathrm{CO}_{2}$ in the short-term. Estimates of methane emissions in the natural gas supply chain have been the subject of much controversy, due to uncertainties associated with estimation methods, data quality and assumptions used. This paper presents a comprehensive compilation of estimated $\mathrm{CO}_{2}$ and methane emissions across the global natural gas supply chain, with the aim of providing a balanced insight for academia, industry and policy makers by summarising the reported data, locating the areas of major uncertainty and identifying where further work is needed to reduce or remove this uncertainty. Overall, the range of documented estimates of methane emissions across the supply chain is vast amongst an aggregation of different geological formations, technologies, plant age, gas composition and regional regulation, not to mention differences in estimation methods. Estimates of combined methane and $\mathrm{CO}_{2}$ emissions ranged from $2-42 \mathrm{~g} \mathrm{CO}_{2}$ eq./ $\mathrm{MJ} \mathrm{HHV}$, whilst methane-only emissions ranged from $0.2 \%-10 \%$ of produced methane. The methane emissions at the extraction stage are the most contentious issue, with limited data available but potentially large impacts associated with well completions for unconventional gas, liquids unloading and also from the transmission stage. From the range of literature estimates, a constrained range of emissions was estimated that reflects the most recent and reliable estimates: total supply chain GHG emissions were estimated to be between 3.6 and $42.4 \mathrm{~g} \mathrm{CO}_{2}$ eq./ MJ HHV, with a central estimate of 10.5. The presence of 'super emitters', a small number of facilities or equipment that cause extremely high emissions, is found across all supply chain stages creating a highly skewed emissions distribution. However, various new technologies, mitigation and maintenance approaches, and legislation are driving significant reductions in methane leakage across the natural gas supply chain.

\section{Introduction}

Natural gas is typically considered to be the lowest carbon fossil fuel and consequently is expected to be relied upon to support the transition to decarbonised global energy systems. In particular, natural gas may have a role in replacing coal for electricity generation and providing flexible supply to support intermittent renewable generators. However, whilst combustion emissions from natural gas are indeed lower than those associated with coal or liquid hydrocarbons per unit of energy delivered [1], this is only part of the story. Firstly, greenhouse gas emissions do not only arise from combustion, but also from the supply chain of natural gas, from finding a reservoir, extracting and processing the gas, through to delivering the gas to the end user. 
Secondly, methane emissions also contribute significantly to natural gas greenhouse gas emissions. Methane is the main component of natural gas and itself is an extremely potent greenhouse gas over short timescales, much more so than carbon dioxide. The relative potency of methane over $\mathrm{CO}_{2}$ reduces over decadal timescales, but if these additional emissions were large enough, the relative climate benefit of gas over coal could be negated. Alvarez et al. [2] suggest that natural gas electricity generation represents a climate improvement over coal for all timescales if methane emissions are lower than $3.2 \%$ (i.e. when methane has its strongest effect directly after emission). Supply chain emissions and methane emissions in particular, have been under scrutiny over the past five years. The dramatic increase in North American shale and tight gas production over this period has led to a large number of studies estimating greenhouse gas emissions and reaching a variety of conclusions [e.g. 2, 3, 4, 5]. Some studies even suggest that natural gas may have a larger impact than coal for power generation. Different studies have utilised various different estimation methods, data and system boundaries, creating an opaqueness regarding the magnitude of natural gas emissions.

This review compiles and reviews the available data on supply chain emissions: what we know and what we need to know in order to understand the role that natural gas should have in a low carbon energy system.

\section{Aims and scope}

The aim of the study is to review the current state of knowledge of methane and $\mathrm{CO}_{2}$ emissions from the natural gas supply chain. Specifically, the study focussed on the following questions:

1. What is the range of estimated methane and $\mathrm{CO}_{2}$ emissions across the natural gas supply chain?

2. What governs the range of estimates within the literature?

a. Different estimation methods

b. Different data and assumptions

c. Natural variation across regions, supply chain routes, processes, equipment and operations.

3. Given the range of emissions and key influencers, what range represents an effective supply chain operation

The scope of the review includes the full supply chain, from exploration to the point of delivery to the end user, as shown in Figure 1. The scope includes all supply chain routes, including liquefied natural gas (LNG) routes, conventional and unconventional extraction, as well as offshore extraction. However, the review excluded associated gas wells, oils wells that co-produce gas (containing less than $350 \mathrm{~m}^{3}$ gas/ barrel of oil [6]) due to co-product allocation issues, which is briefly discussed in the Methodological differences section. The study also excludes end-use combustion stage emissions and emissions from abandoned wells, which may be a significant source of emission [7$10]$. 


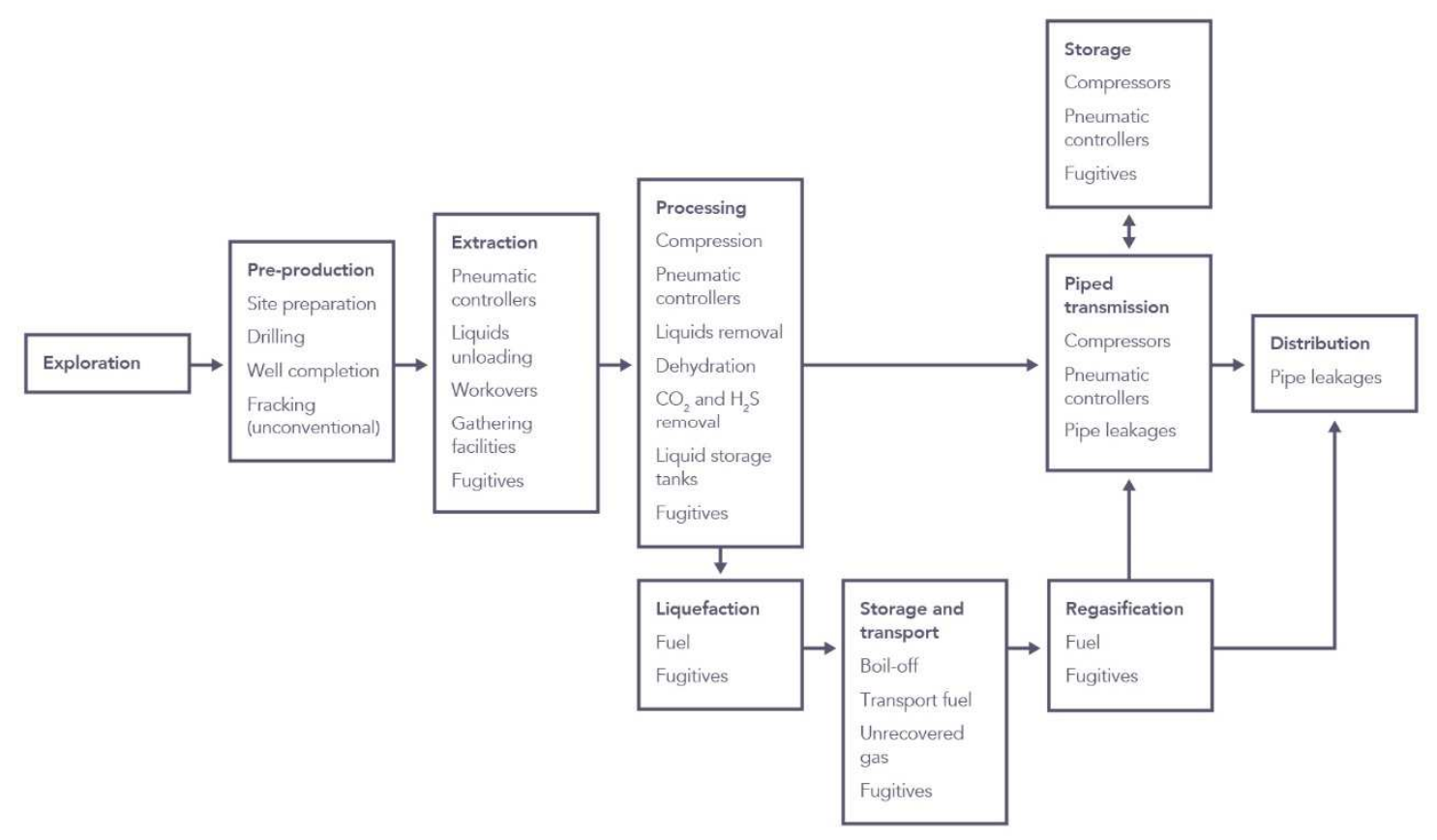

Figure 1. The natural gas supply chain with examples of key emission sources.

A systematic and comprehensive search for related literature was undertaken in December 2014, the details of which can be found in Balcombe et al. [11]. Subsequently to this, a number of important measurement campaigns have been published and we have incorporated these as they have become available. Due to the diversity of the literature reviewed, much of the data had to be converted to comparable units. To quantify supply chain GHG emissions, this study employs the units of $\mathrm{g} \mathrm{CO}_{2}$ eq./ $\mathrm{MJ}$ energy content of delivered natural gas, based on higher heating value (HHV). This unit was selected as most appropriate, as it represents a functional unit without inferring the downstream service (e.g. electricity generation). It was also the most commonly used unit from the literature studied and thus required the least amount of data manipulation. For methane-only emissions, the review defines as the percentage of methane extracted unless otherwise stated.

Where metric conversion was required, a set of standard assumptions were applied. The key assumptions used were: methane Global Warming Potential of 34 (GWP100); the well Estimated Ultimate Recovery of $57 \mathrm{~m} \mathrm{~m}^{3}$; the extracted gas methane fraction of $80 \% \mathrm{vol} / \mathrm{vol}$; and a gas higher heating value of $38.1 \mathrm{MJ} / \mathrm{m}^{3}$.

The following section summarises the literature emissions estimates and the key causes of variation, stage by stage. The presence of 'super emitters' is then described and the availability of data is discussed. A constrained range of emissions from the most recent and reliable data is then described before detailing the key methodological differences in emissions estimation and conclusions and recommendations.

\section{Supply chain emissions}

Overall, 454 papers were collected, of which 250 were selected for a full review based on relevance, robustness and reliability. At least some level of traceability for emissions was required to be included within the review, e.g. a referenceable source or measurement, although the degree of 
transparency was highly variable. The papers were collected from a broad range of institutions and were highly variable with respect to data granularity and method, but the vast majority of the emissions data was from the US.

Estimates of total combined $\mathrm{CO}_{2}$ and methane supply chain emissions were between 2 and $42 \mathrm{~g} \mathrm{CO}_{2}$ eq./ MJ HHV, whilst a small number of estimates of individual supply chain stages were even higher, for example from well completions and liquids unloading processes as shown in Figure 2. Note that the estimated total emissions are published estimates of total supply chain emissions, rather than a summation of the individual categories. Many of the individual stage estimates did not give total supply chain emissions and, likewise many of the papers giving total estimates do not present such granularity in the individual estimates. Estimates of methane-only emissions are similarly variable, from $0 \%$ to over $10 \%$ of total produced methane.

Whilst the range of emissions estimates is large, the vast majority of estimates are at the lowest end of the range for each stage, resulting in a highly skewed distribution of estimates. Again, this is indicated in Figure 2 , showing the $25^{\text {th }}, 50^{\text {th }}$ and $75^{\text {th }}$ percentile estimates at the lowest end of the scale. The emissions for each stage are described in the proceeding section in terms of the range, distribution and the quality of the data.

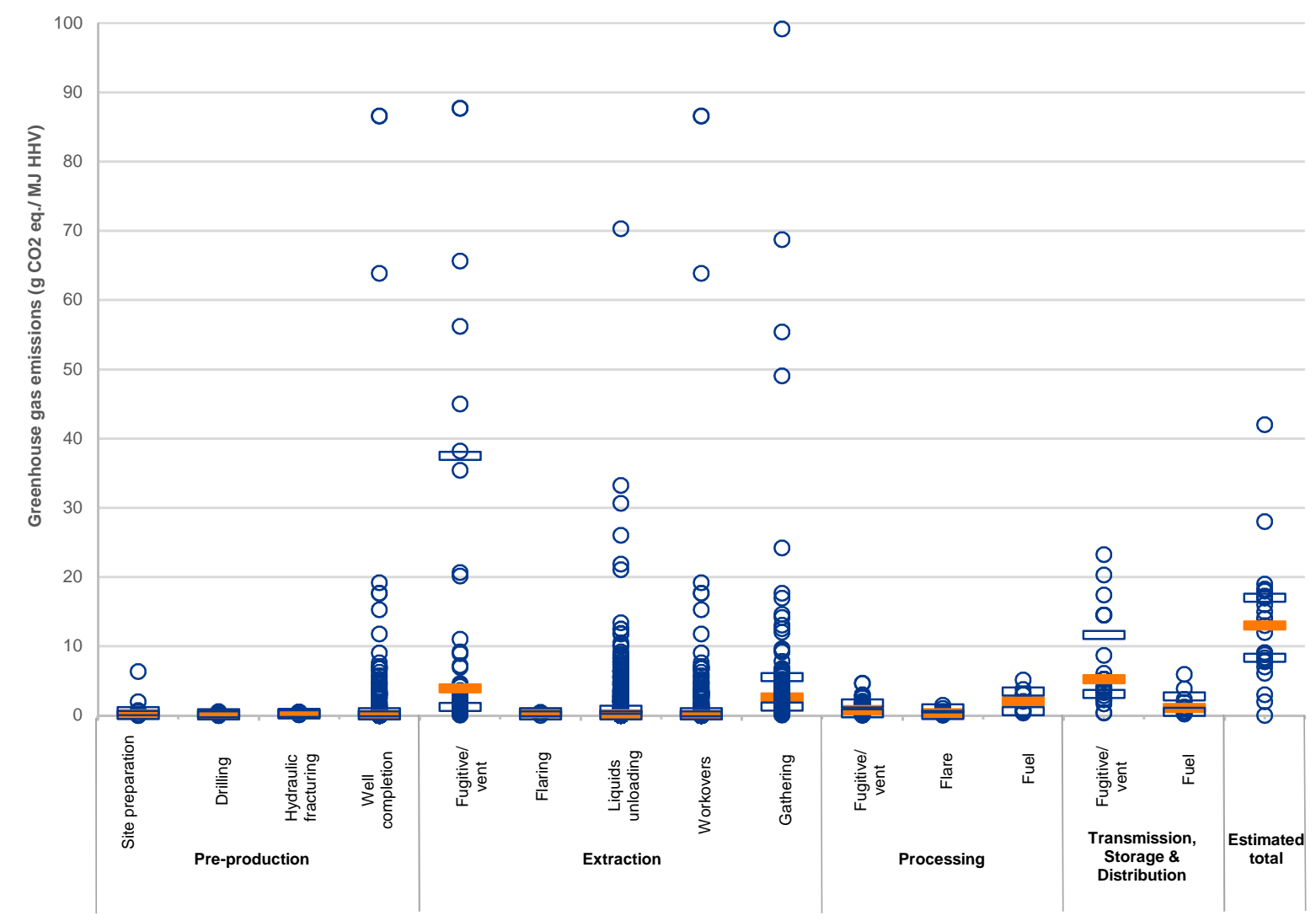




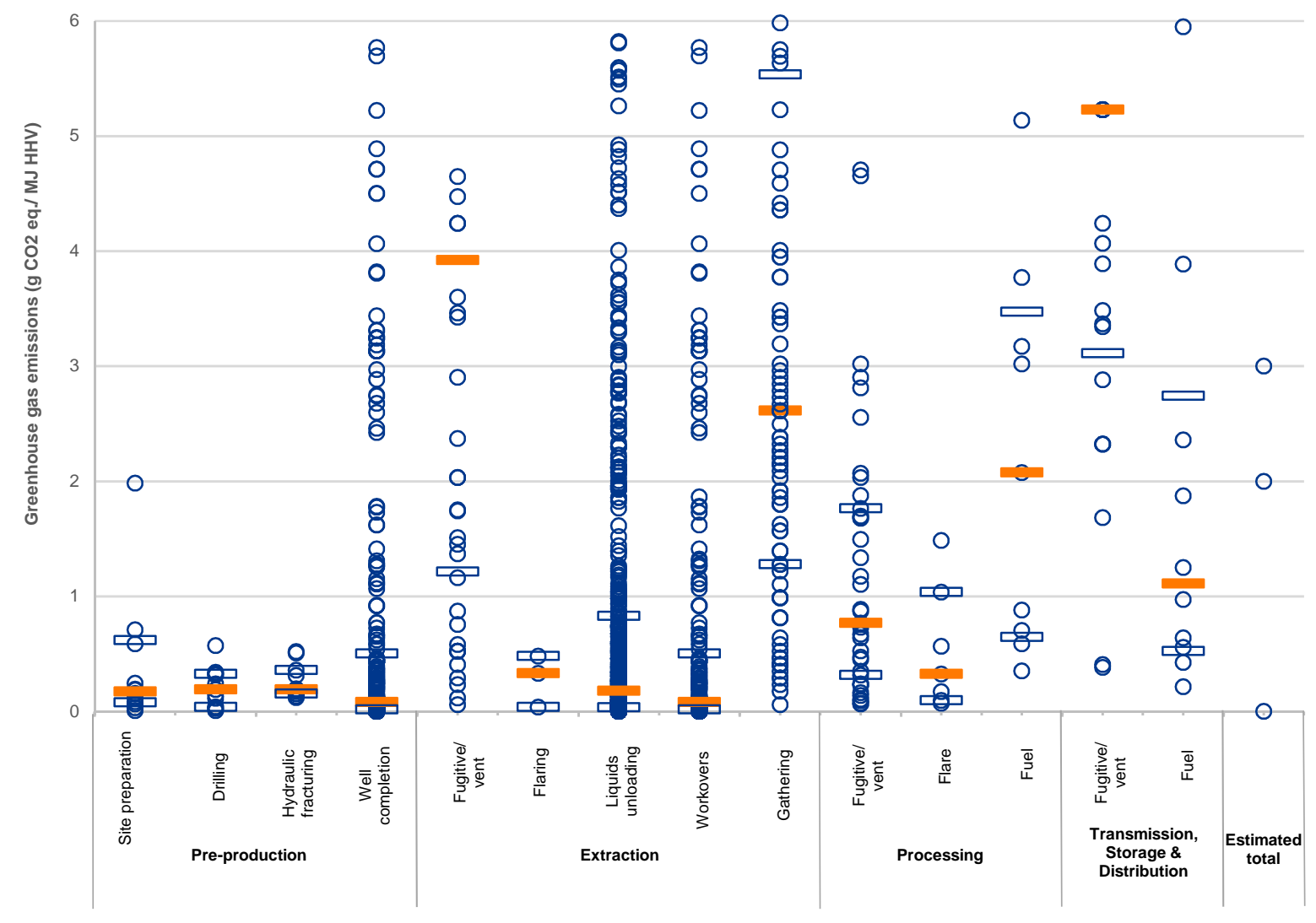

Figure $2 a$ and $2 b$. Literature estimates of combined methane and $\mathrm{CO}_{2}$ emissions from different stages of the natural gas supply chain [11]. Note that the 'estimated total' category is of published estimates of total supply chain emissions, rather than a summation of individual stages. Figure 2 a shows the range of emissions up to $100 \mathrm{~g} \mathrm{CO} 2 \mathrm{eq} . / \mathrm{MJ} H \mathrm{HV}$. Note that there are 6 estimates above $100 \mathrm{~g} \mathrm{CO2} \mathrm{eq./} \mathrm{MJ} \mathrm{under} \mathrm{the} \mathrm{extraction} \mathrm{'fugitive/vent'} \mathrm{category:} \mathrm{232,} \mathrm{285,} \mathrm{304,} \mathrm{618,} 1910$ and $5250 \mathrm{~g} \mathrm{CO} 2$ eq./ MJ. Figure $2 \mathrm{~b}$ shows the range between zero and $6 \mathrm{~g} \mathrm{CO} 2 \mathrm{eq} . / \mathrm{MJ}$, where the majority of estimates lie. Individual estimates are represented by a circle, the median estimate is shown as an orange bar and the $25^{\text {th }} / 75^{\text {th }}$ percentile range is shown as hollow bars. Adapted from [11].

\section{Pre-production}

Pre-production stages include reservoir exploration, site preparation, drilling and well completion. Prior to the completion of a drilled well, both methane and $\mathrm{CO}_{2}$ emissions from pre-production stages are typically assumed to make only a small contribution, but there is very little data available to underpin this assumption, especially for the exploration phase.

\section{Exploration}

Most studies either exclude exploration from the scope [e.g. 12, 13-15] or assume emissions are negligible [e.g. 16]. As exploration includes both geophysical prospecting (e.g. seismic assessment) and exploratory drilling, some emissions of both methane (drilling) and $\mathrm{CO}_{2}$ (fuel use) are likely. Additionally, the emissions associated with unsuccessful exploration should also be accounted for within gas production life cycle assessments, but are typically not so.

\section{Site preparation and drilling}

Site preparation and drilling phase emissions are mostly $\mathrm{CO}_{2}$ emissions from fuel requirements. Site preparation emissions estimates are $0.01-0.6 \mathrm{~g} \mathrm{CO}_{2}$ eq./ $\mathrm{MJ} \mathrm{HHV}[12,17-20]$ and drilling emissions estimates are $0.01-0.6 \mathrm{~g} \mathrm{CO}_{2}$ eq./ MJ HHV $[12,17-23]$. Higher emissions are associated with deeper wells and horizontally drilled wells. However, these stages represent a relatively minor part of total supply chain emissions. 


\section{Well completion}

Whilst there have been relatively few estimates of the above operations, much more consideration has been given to well completions. Well completion is a group of operations that encompass cementing and casing the drilled well, hydraulically fracturing the well where required and flowback of the fracturing fluid prior to the commencement of gas extraction.

Hydraulic fracturing is an energy intense process resulting in $\mathrm{CO}_{2}$ emissions from fuel usage, estimated between 300 and $1,000 \mathrm{t} \mathrm{CO}_{2}$ eq./ well, equivalent to $0.1-0.5 \mathrm{~g} \mathrm{CO}_{2}$ eq./ MJ HHV. However, the estimates of flowback emissions are much more variable. Flowback is the return of the hydraulic fracturing fluid to the surface of the well, where large volumes of the natural gas may also be brought to the surface, with estimates from zero to $6.8 \mathrm{~m} \mathrm{~m}^{3} \mathrm{CH}_{4}$ per completion $[4,5,12,15,16$, $18,19,22-37]$, equivalent to $0-87 \mathrm{~g} \mathrm{CO}_{2}$ eq./ MJ HHV. However, this is not necessarily a realistic representation of global completions emissions. Table 1 gives a breakdown of the completion emissions data. The key differentiating factors between the different estimates are the equipment used, whether they are primary or secondary data and whether the estimates are for conventional or unconventional gas wells. Primary data are defined here as data where methane emissions have been measured, whereas secondary data are based on other studies, assumed or modelled.

Table 1. Summary of methane emission estimates from well completions, split by conventional/ unconventional, primary/ secondary, and RECS/NonRECS [4, 5, 12, 15, 16, 18, 19, 22-37]. Note that many volume estimates are at (American) standard conditions of $15.6^{\circ} \mathrm{C}$ and $1 \mathrm{~atm}$, but some studies do not specify the conditions. REC: Reduced emission completions.

\begin{tabular}{|c|c|c|c|c|c|c|c|}
\hline \multirow[t]{2}{*}{ Well type } & \multirow[t]{2}{*}{ Equipment } & \multirow[t]{2}{*}{ Data } & \multirow{2}{*}{$\begin{array}{c}\text { Sample } \\
\text { size }\end{array}$} & \multicolumn{4}{|c|}{ Emissions (1000 $\mathrm{m}^{3} \mathrm{CH}_{4} /$ completion) } \\
\hline & & & & Mean & Median & Min & Max \\
\hline \multirow{2}{*}{\multicolumn{2}{|c|}{ Conventional }} & Primary & 10 & 4.9 & 5.7 & 0.0 & 7.4 \\
\hline & & Secondary & 8 & 0.9 & 1.0 & 0.0 & 2.0 \\
\hline \multirow{4}{*}{ Unconventional } & \multirow{2}{*}{ RECs } & Primary & 76 & 3.0 & 1.1 & 0.0 & 24.9 \\
\hline & & Secondary & 14 & 39.3 & 15.0 & 0.0 & 210.1 \\
\hline & \multirow{2}{*}{ NonRECs } & Primary & 88 & 11.9 & 5.8 & 0.3 & 100.1 \\
\hline & & Secondary & 73 & 606.0 & 245.8 & 1.3 & 6800.0 \\
\hline
\end{tabular}

Firstly, it must be noted that the primary measurements are significantly lower than the secondary estimates (e.g. those based on engineering calculations). Most of the larger secondary estimates [4, $5,12,24,25,35]$ were published prior to the more recent primary measurements, resulting in conservative assumptions due to a lack of knowledge of expected emissions.

Secondly, whilst unconventional gas emissions estimates are extremely large, estimates for conventional wells are generally low, as these wells tend not to utilise hydraulic fracturing and so there is no flowback stage. Estimates of completion emissions for conventional wells are zero $7,400 \mathrm{~m}^{3} \mathrm{CH}_{4}$ per completion [4, 15, 24, 27, 28, 30,32, 34], equivalent to less than $0.1 \mathrm{~g} \mathrm{CO}_{2}$ eq./ $\mathrm{MJ}$ HHV. It is important to note however that no emissions data for offshore completion activities were found during this review.

Lastly, flowback emissions are governed by whether Reduced Emissions Completions (RECs) are used. RECs are equipment that allow the capture of gas during flowback, either to be sent to the product line, or if this is not feasible, to be flared. The data suggests that the use of this equipment reduces completion emissions by approximately $75-99 \%$ [32, 38-40]. For the most established unconventional gas industry, the US, the use of RECs is compulsory. However once RECs are employed and methane is flared to some degree, resultant $\mathrm{CO}_{2}$ emissions from flaring may become 
significant. For example, the completion measurements by Allen et al. [5] included 13 sites (of 27) which flared methane, where $\mathrm{CO}_{2}$ emissions from flaring accounted for $61 \%$ of $\mathrm{GHG}$ emissions (assuming a flaring efficiency of $98 \%$ and a GWP100 of 34 for methane). Whilst primary estimates of RECs emissions $\left(0-25,000 \mathrm{~m}^{3}\right.$ per completion $\left.[5,12,16,20,28,30]\right)$ are an order of magnitude greater than emissions from conventional wells $\left(0-7,400 \mathrm{~m}^{3} \mathrm{CH}_{4}\right.$ recorded across the literature), the total contribution to supply chain emissions is low at less than $0.3 \mathrm{~g} \mathrm{CO}_{2}$ eq./ MJ HHV. Consequently, when RECs are utilised, unconventional well emissions are comparable to those of conventional wells, because other downstream processes are similar [16].

\section{Extraction}

Once the well is completed, gas production begins. Typical production emissions are from equipment leaks and vents, workover emissions and liquids unloading. Not including workovers and liquids unloading, methane leaks and vents arise from pneumatic device vents, compressors, condensate storage tank vents and fugitive emissions and are mostly estimated to be below $1 \%$ of produced methane $[19,20,28,30,41]$, equivalent to 1 - 11 g CO 2 eq./ MJ HHV. However, recent campaigns have identified a small percentage of wells that exhibit much higher emissions [41, 42], particularly for older wells and lower production rates.

\section{Workovers}

Workovers represent a multitude of operations, including repairing leaks, re-perforating or cleaning the well bore and for unconventional wells, re-fracturing to stimulate the reservoir. Emissions estimates tend to be the same as for well completions, but the number of workovers required per well varies across the literature, from zero to 5 workovers per well lifetime $[29,30,32,38]$. The API suggest that there is variation in workover rates across different well types, with a survey of US wells suggesting $0.3 \%$ of conventional and shale wells conduct workovers per year, whereas $3 \%$ of tight sands wells conduct workovers. There may be other underlying differences contributing to this difference, such as the maturity of the well stock. The vast majority of wells appear to require very few workovers and, at such low rates, the emissions contribution is likely to be very low.

\section{Liquids Unloading}

Liquids unloading is also a key emissions source, which involves removing the liquids that accumulate at the bottom of the well in order to improve gas flow. This can be via various mechanisms, such as blowdowns, plunger lifts, artificial lifts, velocity tubing, well swabbing or using foaming agents [43]. The only documented emissions profiles are from blowdown operations and plunger lifts, where emissions vary significantly, with estimates from zero to $500,000 \mathrm{~m}^{3} \mathrm{CH}_{4} /$ year $[4,5,14,15,24,27-30,37,44]$. The quantity of emissions depends upon a number of factors:

- Well characteristics (i.e. gas flow, presence of liquids within the reservoir). Some wells will not require unloading at all whilst others, particularly low pressure/ low production onshore wells, may require frequent unloading.

- Well age. Wells only require unloading after a period of time when gas production has lowered and liquids have accumulated at the bottom of the well. The point at which unloading is required varies by well.

- Different equipment used to perform unloading have highly varied emissions characteristics.

- Operating procedure. A large variation in emissions from automated plunger lifts suggests that some of these operations could be significantly improved in terms of emissions reduction. 
Figure 3 illustrates the average liquids unloading emissions data across different sources, split by primary/ secondary data and by process (blowdown, manual plunger and automatic plunger lift) [4, $5,14,15,24,27-30,37,44]$. Somewhat surprisingly, facilities with an automatic plunger lift emitted the most within the comprehensive study by Allen et al. [44], due to the higher frequency of unloading events. It is incorrect to assume that automated plunger lifts cause higher emissions, but this may be due to this equipment being installed on higher producing wells, or wells that require more frequent unloading events (e.g. greater water content). It is likely that the equipment used affects the level of emissions greatly, but this is not quantifiable with current data.

\begin{tabular}{|c|c|c|c|c|}
\hline Data & Reference & Plunger & $\begin{array}{c}\text { Emissions/ } \\
\text { event } \\
\left(\mathrm{m}^{3} \mathrm{CH}_{4}\right)\end{array}$ & $\begin{array}{c}\text { Events/ } \\
\text { year }\end{array}$ \\
\hline \multirow{6}{*}{ 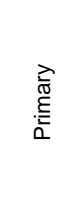 } & Allen 2015 & Yes- Auto & 34 & 2,445 \\
\hline & Allen 2015 & No & 716 & 33 \\
\hline & Allen 2013 & No & 1,616 & 6 \\
\hline & Allen 2015 & Yes- Man & 273 & 13 \\
\hline & GHG RP 2015 & Yes & 27 & 120 \\
\hline & GHG RP 2015 & No & 18 & 132 \\
\hline \multirow{10}{*}{ 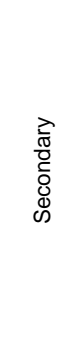 } & ICF 2014 & Yes & - & - \\
\hline & Shires 2012 & Yes & 2 & 344 \\
\hline & Shires 2012 & No & 58 & 33 \\
\hline & ICF 2014 & No & - & - \\
\hline & Burnham 2011 & Mix & - & - \\
\hline & Venkatesh 2011 & Mix & - & - \\
\hline & Shahriar 2014 & Mix & 489 & 31 \\
\hline & Skone 2011 & Mix & 489 & 31 \\
\hline & Howarth 2011 [3] & Mix & - & - \\
\hline & O'Donoughue 2014 & Mix & - & - \\
\hline
\end{tabular}

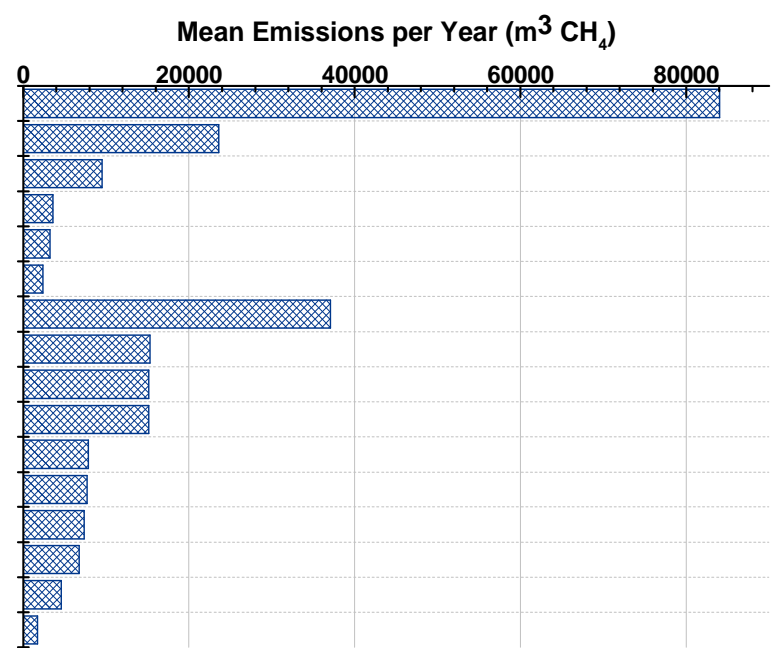

Figure 3. Average methane emissions associated with liquids unloading from various primary and secondary literature sources $[4,5,14,15,24,27-30,37,44]$. Adapted from [11].

To convert annual unloading emissions into levelised estimates, it was assumed that these emissions occur for half of the lifespan of the well, as no other data was available. Varying this assumption may have a significant impact on the life cycle GHG emissions, but there is little data on when liquids unloading is required. This should be the subject of further research in order to gain a more accurate determination of unloading GHG emissions.

$\mathrm{CO}_{2}$ emissions may also occur via flaring, but the only measured data found was for the GHG Reporting Program [24], suggesting that $\mathrm{CO}_{2}$ emissions contribute less than $1 \%$ of total GHG emissions. However, there is little transparency in this dataset and the estimation method is largely unknown.

Whilst there appear to be some extremely large emitters, most wells do not require liquids unloading in the early years of production and according to API/ ANGA, $87 \%$ of wells surveyed do not vent at all whilst unloading. However, this figure represents a cross-section of US onshore wells in 2012 and consequently the impact of well age on vent rates during unloading is unknown. Given the shear variability and the potential contribution to total emissions, further research is required to create a sound understanding of the factors affecting unloading emissions across the life span of a well and across different regions and well types.

\section{Gathering stations}

The accounting for gas gathering facility emissions, which occurs downstream of the extraction point but prior to processing, is inconsistent within the literature. There are very few primary estimates of 
gathering facility emissions, but the most recent and comprehensive study suggests high variability in methane emissions [45]. Out of 104 gathering facilities, median emissions were $0.45 \%$ of throughput, but with an extremely large heavy tail. Emissions were strongly correlated with the throughput of the station, with far lower proportional emissions associated with the larger facilities. Emissions were typically from liquid tank vents, leaking valves and pipes, dehydrator venting and compressor seal vents and exhaust. $\mathrm{CO}_{2}$ emissions are also likely to occur from fuel usage for compressors and dehydrators [45], but no estimates were found within the literature.

\section{Processing}

Total GHG emissions across the processing stage have been estimated as $1-13 \mathrm{~g} \mathrm{CO}_{2}$ eq./ MJ HHV $[4,13,17-19,23,28,30,36,46-49]$. The main source of the magnitude of emissions is the fugitive and vented methane, and $\mathrm{CO}_{2}$ emissions from fuel for equipment such as compressors and reboilers as shown in Figure 4. Large ranges of energy demands are cited, from $0.5 \%$ to $9 \%$ of produced gas used as fuel $[13,19,30]$. Assuming an efficient combustion, this is equivalent to approximately $0.4-$ $5.1 \mathrm{~g} \mathrm{CO}_{2}$ eq./ MJ HHV. The energy requirement is dependent on the composition of the extracted natural gas (i.e. how much treatment is needed to produce the sales-worthy gas) and on the well pressure (i.e. how much compression is required to pressurise the gas), but there is little information on quantifying this variation.

Methane emissions tend to be estimated at less than $0.5 \%$ of methane production, with an average across studies of $0.21 \%[4,13,28,30,45-47,49]$, equivalent to $1.2 \mathrm{~g} \mathrm{CO}_{2}$ eq./ MJ HHV. Leakages are lower than at extraction facilities as processing facilities tend to be permanently manned, as opposed to extraction sites [45]. Of these methane emissions, the main sources are from liquid storage tank vents (flashing liquids), pneumatic valve venting and compressor and pipework flange leaks.

Another large source of $\mathrm{GHG}$ emissions is from venting $\mathrm{CO}_{2}$ during the $\mathrm{CO}_{2}$ removal phase. The magnitude of emissions is dependent on the $\mathrm{CO}_{2}$ content of the extracted gas and could contribute up to $50 \%$ of the processing GHG emissions [28]. A small amount of gas must be flared as well, typically less than $0.5 \%$ of produced gas $[13,30]$. 


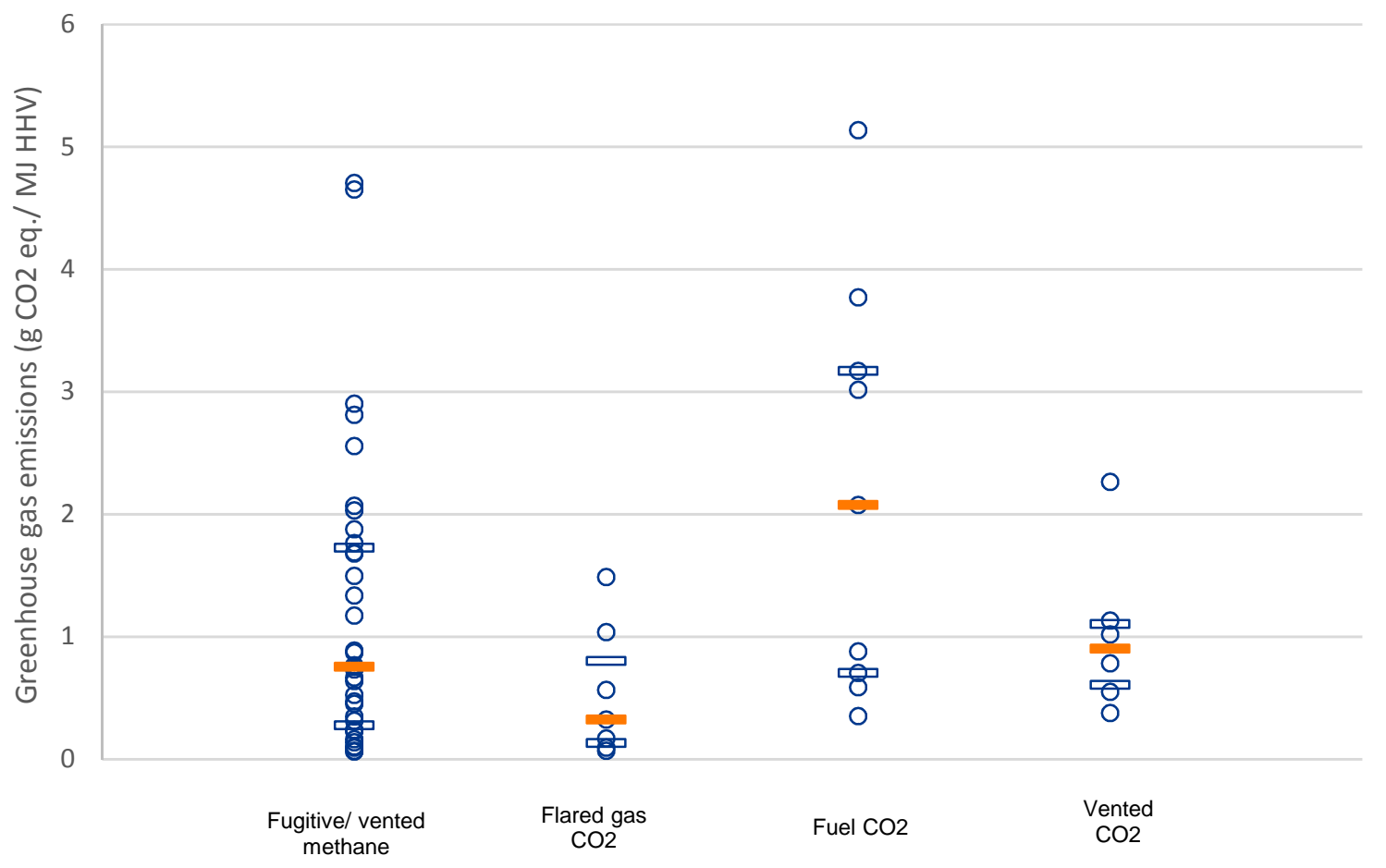

Figure 4. Greenhouse gas emission estimates associated with natural gas processing, by emission source category [4, 13, 17-19, 23, 28, 30, 36, 46-49]. Individual estimates are represented by a circle, the median estimates are shown as an orange bar and the $25^{\text {th }} / 75^{\text {th }}$ percentile range is shown as hollow bars.

\section{Transmission and Storage}

Estimates of total emissions from the transmission phase are $0.2-15.5 \mathrm{~g} \mathrm{CO}_{2}$ eq./ MJ HHV $[4,19,28$, $30,36,37,50-59]$, which arise from $\mathrm{CO}_{2}$ combustion emissions from gas-fuelled compressors and methane leaks and vents from pipework, compressors and gas-driven pneumatic devices. Estimates for total methane leaks and vents across the transmission stage are between $0.05 \%$ and $4 \%$ of total produced methane $[19,30,31,36,50-55,57,60]$, equivalent to $0.1-15.2 \mathrm{~g} \mathrm{CO}_{2}$ eq./ MJ HHV. However, estimates above $1.6 \%$ have used estimates based on 'lost and unaccounted for gas', which is generally considered to be a flawed approach that leads to overestimation $[4,31,60,61]$.

Estimates of fuel usage for compressors are between $0.5 \%$ and $8.6 \%$ of total gas production [19, 30, $36,51,52,54]$, which is equivalent to approximately $0.2-6 \mathrm{~g} \mathrm{CO}_{2}$ eq./ MJ HHV. The quantity of emissions is governed by the transport distance required, as well as various technological characteristics. Transmission pipelines require compressor stations every 80 to 160 kilometres [50] and average transport distances are often cited as approximately $1,000 \mathrm{~km}[30,62]$, although this is highly variable across different networks and may be much more $[55,62]$.

As part of transmission networks, storage facilities provide flexibility between gas supply and demand, comprising the underground storage site, compressors and dehydrator facilities [63]. The main sources of storage methane emissions are from compressors and pneumatics, similar to transmission compressor stations $[64,65]$. There is very little information on storage sites and within LCA studies they are typically considered as part of the transmission network.

\section{Distribution}

There are very few estimates of emissions from distribution networks, which would be largely methane emissions from pipework leaks and vents and leaks from metering and regulating stations 
[31, 66-70]. Estimates are in the range of $0.1-1.9 \%$ of methane produced [66-70], equivalent to 0.3 $-7.2 \mathrm{~g} \mathrm{CO}_{2}$ eq./ MJ HHV. Three studies have attempted to measure the emissions in city distribution networks [71-73] and found significant variation across different cities. Greater emissions were from areas with more cast iron pipework [72], where unprotected metallic pipelines have high corrosion rates, which does not occur for plastic analogues.

\section{Liquefied natural gas}

The LNG supply chain route is used for long distance transport where piped transmission is not feasible or economically viable. The LNG stages consist of liquefaction, transportation by LNG tanker and regasification by heating the gas back to atmospheric temperature. Total emissions from LNG stages are estimated to be $11.2-31.1 \mathrm{~g} \mathrm{CO}_{2}$ eq./ MJ HHV [74-84], with the largest contribution coming from the liquefaction process as shown in Figure 5. Several papers estimate emissions from LNG but there is less depth and transparency in the study of methane emissions and most of the source data used is not publically available.

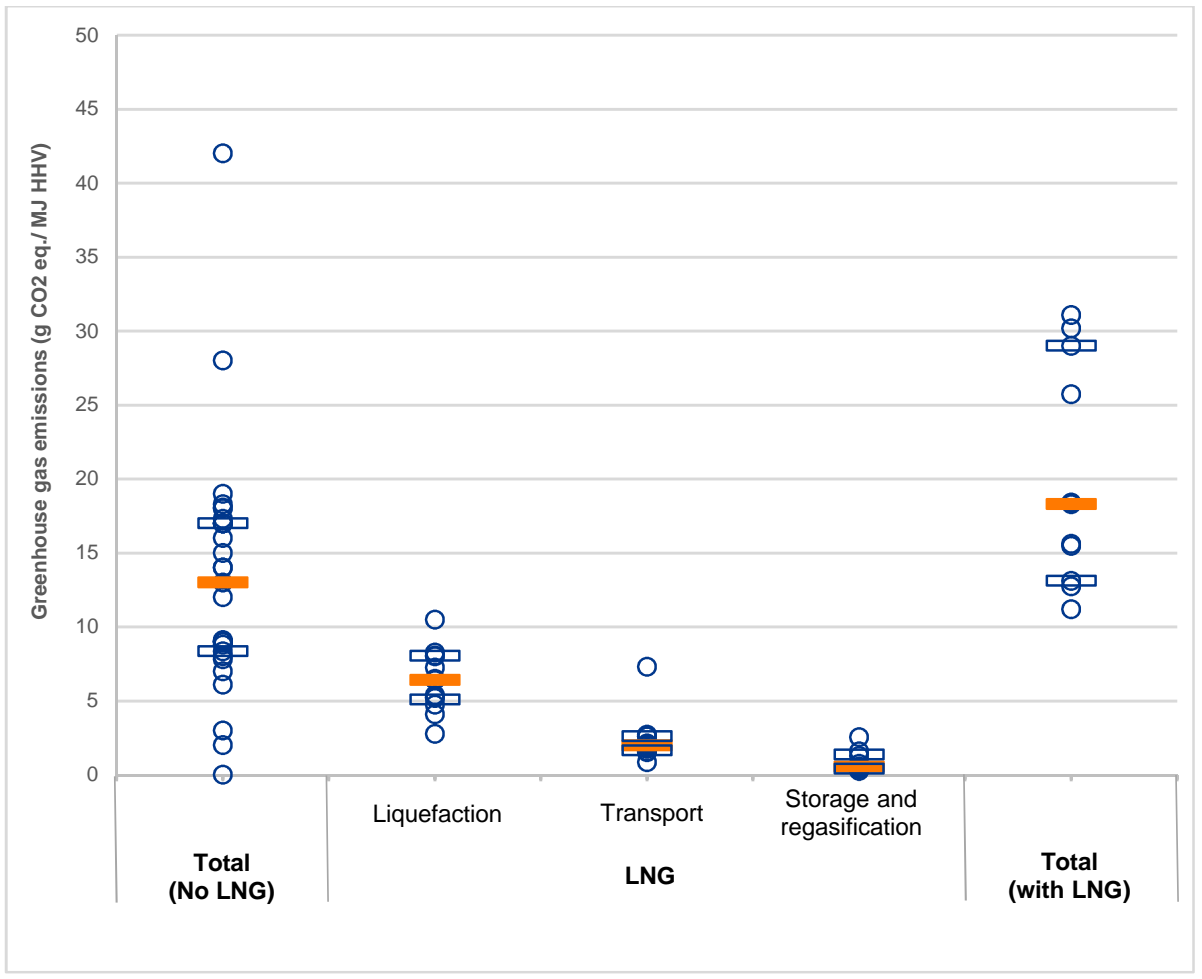

Figure 5. Greenhouse gas emission estimates for each LNG stage, compared with total non-LNG supply chain emissions estimates [74-80, 82-84]. Adapted from [11].

$\mathrm{CO}_{2}$ emissions from fuel combustion is the largest contributor to $\mathrm{LNG}$ GHG emissions overall. The liquefaction energy demand is normally assumed to be $8-12 \%$ of the natural gas throughput, or from 4.1 to $7.7 \mathrm{~g} \mathrm{CO}_{2}$ eq./ $\mathrm{MJ}[74-77,79,84,85]$. Natural gas is mostly used as the fuel for the liquefaction process, with diesel or electricity contributing a very small quantity (e.g. Choi and Song [77] assume $2 \%$ of energy is from electricity). Methane emission estimates from leaks and venting vary from 0.01 to $4.22 \mathrm{~g} \mathrm{CO}_{2}$ eq./MJ HHV [75, 77-81]. However, there is limited transparency of the sources of these emissions and there is very little detail in particular on fugitive emissions.

The transportation emissions estimates for LNG are dominated by the $\mathrm{CO}_{2}$ combustion emissions associated with propulsion of the LNG tankers, estimated as between 0.9 and $7.3 \mathrm{~g} \mathrm{CO} 2 \mathrm{eq} . / \mathrm{MJ}$ [74, 
$76,78-80,82-84,86,87]$. These emissions vary considerably depending upon the size, distance, efficiency and specific operating conditions of the tankers [88]. Emission factors have been estimated to vary between 9.4 and $14.4 \mathrm{~g}$ of $\mathrm{CO}_{2} /$ tonne-km [88-90].

Methane emissions associated with venting and leaks during transportation are generally poorly accounted for but may represent a significant proportion of the transportation GHG emissions: Choi and Song [77] suggest methane could contribute between one and two thirds of transportation GHG emissions. The main source of methane emission is boil-of gas (BOG), which results from heat ingression to the cryogenic storage. Boil-off rates during storage and shipping have been reported to be as high as $0.1 \%-0.25 \%$ per day $[76,91]$, but the recovery rate is estimated to be around $80 \%$ as it is re-liquefied or used as fuel for the tankers [77, 83]. Manufacturers of LNG tankers typically advertise boil-off rates of $0.25 \%$ per day, but can actually go up to 75 days without having to vent any boil-off gas [83].

Once LNG reaches its destination, it is stored, regasified and distributed. Overall, estimations for the regasification process represent a smaller contribution to the supply chain, $0.26-2.53 \mathrm{~g} \mathrm{CO}_{2}$ eq./MJ $[74,76-80,84,87]$, mostly as a result of $\mathrm{CO}_{2}$ combustion emissions for energy usage. It is typically assumed that $1.5 \%$ of natural gas throughput is required for fuel for pumps, compressors and reboilers [84, 87]. Cryogenic energy efficiency gains has potential to reduce emissions significantly, as waste heat can be utilised for industrial processes such as air separation [78].

\section{Super emitters}

An extremely large range of emissions has been estimated across the literature, with a skewed distribution for many stages. One reason for this is the presence of 'super emitters'. These super emitters are a small number of facilities or equipment within the supply chain that emit disproportionately large quantities $[3,92]$ and have been identified frequently within the literature, particularly within the last 4 years. They are responsible for increasing the greenhouse gas emissions of the whole sector and potentially skewing the average emission factors associated with each supply chain stage. Table 2 provides a range of example studies where evidence of super emitters was identified.

Table 2. Evidence of super emitters across the supply chain, sorted by supply chain stage.

\begin{tabular}{|c|c|c|c|}
\hline Reference & Stage & Region & Description \\
\hline ERG 2011 [93] & Extraction & US & $\begin{array}{l}10 \% \text { of gas wells emitted } 70 \% \text { of fugitive methane } \\
\text { emissions. }\end{array}$ \\
\hline Allen 2015 [44] & Liquids unloading & US & $\begin{array}{l}20 \% \text { of wells with plunger lifts that vent account for } 70 \% \text { of } \\
\text { plunger venting emissions. }\end{array}$ \\
\hline Shires 2012 [29] & Liquids unloading & US & $\begin{array}{l}10 \% \text { of total well population account for over } 50 \% \text { of } \\
\text { liquids unloading emissions. }\end{array}$ \\
\hline Shires 2012 [29] & Liquids unloading & US & $\begin{array}{l}3 \% \text { of wells without plunger lifts account for over } 90 \% \text { of } \\
\text { no-plunger unloading emissions. }\end{array}$ \\
\hline GHG RP 2015 [94] & Liquids unloading & US & $\begin{array}{l}10 \% \text { of well population in } 2013 \text { account for } 65 \% \text { of total } \\
\text { unloading emissions. }\end{array}$ \\
\hline Mitchell 2015 [45] & Gathering & US & $\begin{array}{l}30 \% \text { of gathering sites accounted for } 80 \% \text { of fugitive } \\
\text { methane emissions. }\end{array}$ \\
\hline
\end{tabular}




\begin{tabular}{|c|c|c|c|}
\hline Reference & Stage & Region & Description \\
\hline Mitchell 2015 [45] & Gathering & US & $\begin{array}{l}\text { Fugitive emissions were over } 5 \% \text { of production for } 6 \text { out of } \\
108 \text { gathering sites, but less than } 1 \% \text { for } 85 \text { and less than } \\
0.1 \% \text { for } 19 \text {. }\end{array}$ \\
\hline NGML 2006 [47] & $\begin{array}{l}\text { Extraction/ } \\
\text { Gathering/ } \\
\text { Processing }\end{array}$ & US & $\begin{array}{l}\text { Top } 10 \text { leaks from each facility studied ( } 12 \text { well sites, } 7 \\
\text { gathering compressor stations, } 5 \text { processing facilities) } \\
\text { contribute } 58 \% \text { of total leak emissions. }\end{array}$ \\
\hline Clearstone 2002 [46] & Processing & US & $\begin{array}{l}\text { The top } 10 \text { equipment leaks from each facility studied ( } 4 \\
\text { processing plants) contributed } 54 \% \text { of leak emissions. }\end{array}$ \\
\hline $\begin{array}{l}\text { Lechtenboehmer } \\
2007 \text { [53] }\end{array}$ & Transmission & Russia & $\begin{array}{l}0.5 \% \text { of compressor and valve components account for } \\
90 \% \text { of leaks in the transmission network. }\end{array}$ \\
\hline Harrison 2011 [95] & Compressor stations & US & $\begin{array}{l}1 \text { leak out of } 2,800 \text { sampled valves and flanges contributed } \\
29 \% \text { of the leaked emissions measured. }\end{array}$ \\
\hline $\begin{array}{l}\text { Subramanian } 2015 \\
\text { [65] }\end{array}$ & Compressor stations & US & $\begin{array}{l}10 \% \text { of compressor stations account for } 50 \% \text { of compressor } \\
\text { venting emissions. }\end{array}$ \\
\hline Venugopal 2013 [96] & Compressor stations & Canada & $\begin{array}{l}\text { Compressor venting emissions were } 4 \text { times higher than } \\
\text { those estimated in Lechtenbohmer et al. [53] due to the } \\
\text { inclusion of older plant equipment. }\end{array}$ \\
\hline Allen 2015 [97] & Pneumatics & US & $\begin{array}{l}20 \% \text { of pneumatic devices account for } 96 \% \text { of pneumatic } \\
\text { venting emissions }\end{array}$ \\
\hline Lamb et al. 2015 [66] & Distribution & US & $\begin{array}{l}3 \text { individual pipeline leaks (of } 230 \text { ) account for } 50 \% \text { of total } \\
\text { emissions. }\end{array}$ \\
\hline
\end{tabular}

The causes of such high emissions are likely to be due to the utilisation of inefficient equipment that is either not the best-available technique for the duty, too old, or has failed due to insufficient operation, maintenance and monitoring procedures [45, 92]. It is the authors' opinion that if appropriate operational control and maintenance procedures were carried out, these high emissions could be largely eliminated. One study [92] suggests that if a policy-intervention successfully reduced emissions from these facilities to 'normal' levels, total supply chain emissions would be reduced by $65-87 \%$. In reality this would be difficult to achieve as the super-emitters within a group of facilities may change over time as the emitting equipment is identified/ fixed and others become larger emitters. However there is clearly great potential in targeting super-emitters for cost-effective supply-chain emissions reduction. It is worth noting that the elimination of high emissions would most likely economically benefit these facilities, as a high emission of gas equates to a large loss of product. Even so, super emitters still occur and thus it should be the responsibility of gas regulators to ensure these emissions are detected and eliminated.

\section{Data availability}

Historically there has been a lack of data on supply chain emissions. Most studies using secondary data rely on the US Environmental Protection Agency (EPA) data from 1996, which remains the most comprehensive dataset available for conventional well data. The original study [69] measured methane and $\mathrm{CO}_{2}$ emission rates from devices across 6 gas plants and 24 oil and gas production facilities. Each year, the EPA assesses whether the data is representative and publishes an estimate of the annual GHG emissions associated with various industries, including natural gas production. Significant revisions have been made to the EPA emission factors in the past 5 years, particularly in 
response to increased unconventional drilling activity. The current set of EPA emission factors are an aggregation of multiple data sets with an unknown representativeness [98].

Additionally, in 2011 the US EPA began publishing data from the GHG reporting program (GHGRP) [24], a database of reported emissions from high emitting facilities (greater than $25,000 \mathrm{t} \mathrm{CO}$ eq. emissions per year). The data collected represents approximately $85 \%$ of the US GHG inventory [99] and is used to inform improvements to the emission factors used within the US GHG inventory [31]. However, whilst this is a potentially useful data source, the representativeness of the sample is lacking due to a lack of transparency, excluded emissions sources [100] and the boundary on the size of the facility capacity.

Since 2011, a large amount of new data has been collected. New data has improved our understanding of the impacts of both conventional and unconventional gas, in particular with respect to:

- well completion emissions for unconventional gas [3, 5, 32, 34, 101];

- liquids unloading for all gas wells [29, 44]; and

- specific equipment and pipeline emissions, such as compressors and pneumatically controlled devices $[5,29,45,65,66,95,97,102,103]$.

However, there remains a lack of representative point-source data and an understanding of emissions variation across regions and over time, in particular with regards to extraction from coal bed methane, liquids unloading and pipework leaks from transmission, storage and distribution. Perhaps the largest gap in available data is for offshore extraction emissions: only one study on offshore gas extraction emissions has been found [30]. Additionally, the transparency of LNG emissions estimates is limited, especially with respect to methane emissions.

In terms of regional distribution of data, all of the upstream data used in this analysis either utilised US emission estimates or conducted measurements within North America. More data is available from Russia for the transmission stage, but data from these sources $[52,53,60]$, is opaque and thus are limited in terms of reliability and applicability to other regions. As regional regulation is likely to impact emissions levels, the emissions data from the US may well not be representative of other natural gas producing regions.

\section{Constrained emissions estimate}

It is clear that the very large aggregated range of literature estimates represents a broad mix of data sources, regions, supply chain routes, equipment, assumptions and estimation methods. In order to represent the variation in emissions rather than estimation methods, we present a constrained range of emissions for each stage with the most recent or reliable data, described below. This constrained range (named CON in this paper) represents the likely range of emissions seen across the natural gas supply chain. For this range, the minimum, median and maximum values for each stage are given. Due to the skewed distribution and presence of super emitters across the supply chain, the maximum values are extremely high, often one or two orders of magnitude higher than the median values. In order to illustrate the relatively constrained range within which the vast majority of estimates lie, the $95^{\text {th }}$ percentile estimates are also detailed, which are often significantly

lower than the maximum values. Note, this paper does not present the total summation of the maximum supply chain stage estimates, as we believe this to be misleading: it is unlikely that these maximum emissions, which are exhibited by a small number of equipment or facilities, would occur 
for each stage across a single supply chain. For each of the supply chain stages, the derivation is described below and summarised in Table 3 and Table 4.

Overall, the constrained range demonstrates both the extreme variability in emissions and the likelihood that the majority of supply chains exhibit relatively low emissions: the median value is reduced from 13 to $10.6 \mathrm{~g} \mathrm{CO}_{2}$ eq./ MJ HHV, whereas the $95^{\text {th }}$ percentile estimate is $42.4 \mathrm{~g} \mathrm{CO}_{2}$ eq./ MJ HHV. To contextualise the scale of these emissions, natural gas power plants typically emit approximately $50 \mathrm{~g} \mathrm{CO}_{2} / \mathrm{MJ} \mathrm{HHV}$, which means that supply chain emissions would represent between $5 \%$ and $43 \%$ of total emissions, with a median estimate of $16 \%$.

The constrained range is similar to the estimated total range found within the literature $(0-42 \mathrm{~g}$ $\mathrm{CO}_{2}$ eq./ MJ HHV). This is rather surprising considering the lack of detail often given to supply chain emissions. It could be explained as the lack of accounting for some emission sources (e.g. gathering stations) is counterbalanced against the overestimates of others (e.g. well completion emissions).

The contribution of methane and $\mathrm{CO}_{2}$ to the total supply chain emissions is shown in Figure 6 for the central emissions estimate. This shows that, using a GWP100 of 34, methane is the dominant contributor to supply chain emissions at $53 \%$. However, for the $95^{\text {th }}$ Percentile estimate, methane contributes a much larger proportion of total supply chain emissions, $69 \%$.

For pre-production the CON range is the same as the raw literature with the exception of well completions. As described previously, the primary measurement data has shown the secondary estimates to be over-conservative. Consequently, the CON figures represent the minimum, median and maximum values from only the primary data.

For extraction 'normal operation' emissions, the Omara et al. [41] dataset of 35 production sites was used for the constrained scenario. The data from Omara et al. was normalised by well production rate, such that the percentile estimates more accurately reflect the distribution by gas volume rather than by well site. This reduced the median estimate significantly: from 3.9 to $0.3 \mathrm{~g}$ CO2 eq./ MJ HHV, which is equivalent to a methane loss of $0.05 \%$ of production.

For the liquids unloading range, the results are the same as the literature estimates, which are dominated and bound by the most recent primary measurements.

As the emissions associated with workovers are related to those from well completions, the workover estimates reduced similarly. The frequency of workovers has been reduced from the literature average estimate of 1.8 times per well life (of 30 years) to once per well life for the central estimate, which is comparable to more recent estimates of workover rates [29]. The high estimate of 5 workovers per well life represents the broad range exhibited across different regions [29].

As with the extraction 'normal operation', the gathering emissions data from Mitchell et al. [45] were normalised by throughput resulting in a reduction in median emissions from 2.6 to $0.4 \mathrm{~g} \mathrm{CO} 2$ eq./ MJ HHV, equivalent to $0.07 \%$ methane emissions.

The processing emissions are the same as the minimum, median and maximum raw literature figures.

Transmission, storage and distribution emissions consist largely of methane leaks and vents, and combustion emissions from compressor fuel. Whilst the estimates of compressor fuel emissions were kept the same for the revised estimate, methane leaks and vents were reduced significantly. A number of studies utilised the 'lost and unaccounted for' method of estimating fugitive methane, 
which has been shown to overestimate losses. These estimates were excluded to give a reduced emissions range of $0.1 \%-1.1 \%$ of gas produced.

With regards to emissions associated with LNG supply chains, the revised estimates were kept the same as the literature values in the absence of more information. Note, in order to account for LNG supply chain emissions per MJ of delivered natural gas, the emissions from the rest of the supply chain stages increase slightly due to the greater gas 'loss' over the LNG stages, as shown in Table 4.

It is highly likely that these supply chain emissions could be reduced further with the use of effective equipment and operation. Targeting emissions reductions is a multi-faceted issue and should could be the subject of further research, as such an estimate could contribute to further determining the potential role of gas in decarbonising global energy systems.

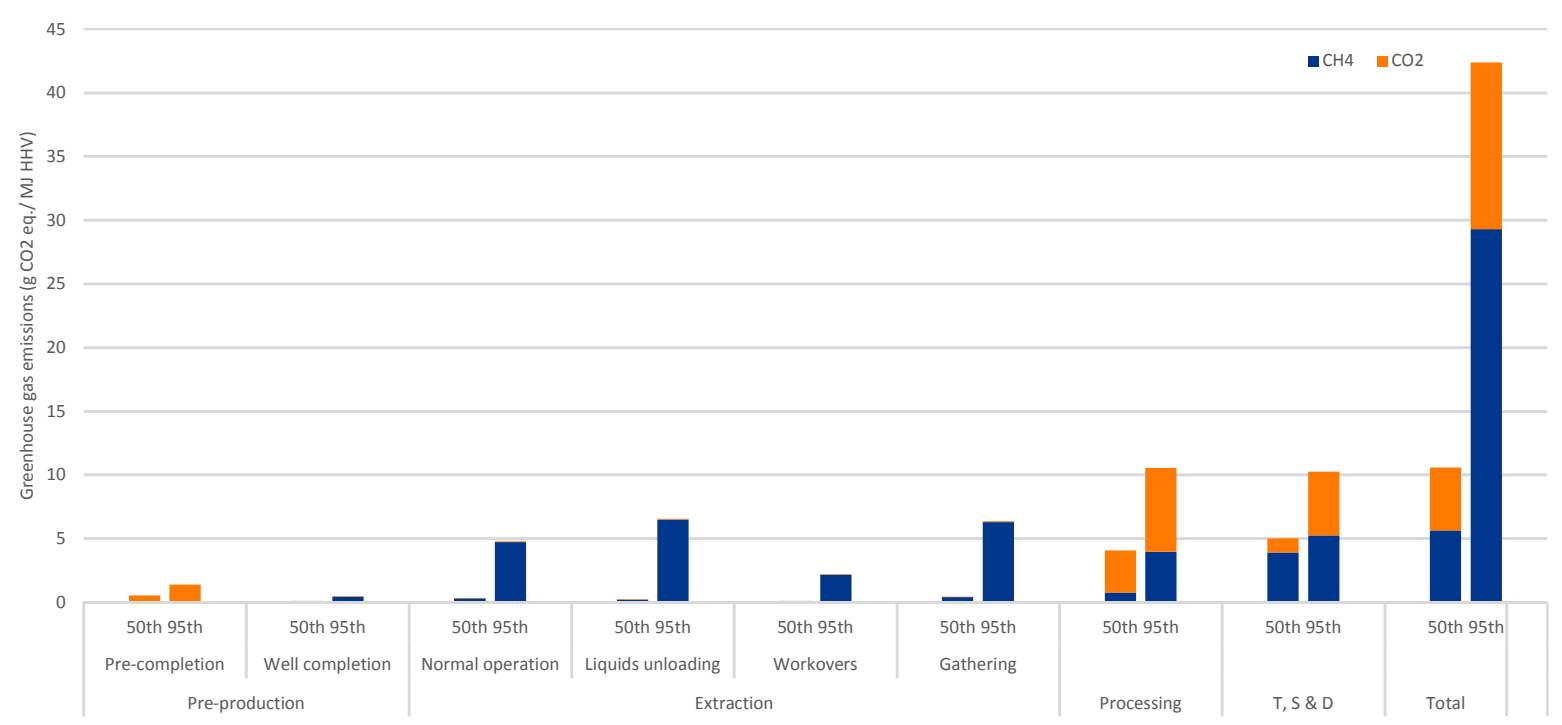

Figure 6. Median (50th percentile) and $95^{\text {th }}$ percentile CON estimate of greenhouse gas emissions for each section of the supply chain, with proportional contributions from methane (blue) and carbon dioxide (orange). 
Table 3. Summary of literature emissions estimates and revised CON estimates for each supply chain stage. For the revised median estimate, the proportional contribution of methane is also given. The median revised estimate is also given in three other functional units: per $k$ Wh of electricity generated, per $m^{3}$ of gas produced from a well (at $0^{\circ} \mathrm{C}$ and 1 atm) and the methane emitted as a percentage of methane extracted.

\begin{tabular}{|c|c|c|c|c|c|c|c|c|c|c|c|}
\hline \multirow[b]{2}{*}{ Supply chain stage } & \multicolumn{3}{|c|}{$\begin{array}{c}\text { Raw Literature } \\
\text { (g CO} 2 \text { eq./ MJ HHV) }\end{array}$} & \multicolumn{5}{|c|}{$\begin{array}{l}\text { Constrained estimate (CON) } \\
\text { (g CO2 eq./ MJ HHV) }\end{array}$} & \multicolumn{3}{|c|}{$\begin{array}{l}\text { Median CON estimate in other functional } \\
\text { units: }\end{array}$} \\
\hline & Minimum & Median & Maximum & Minimum & & $\% \mathrm{CH}_{4}$ & $\begin{array}{r}\text { 95th } \mathrm{Pe} \\
\quad(\max \end{array}$ & $\begin{array}{l}\text { ntile } \\
m)\end{array}$ & $\begin{array}{l}\text { g CO2 eq./ } \\
\text { kWh } \\
\text { electricity } \\
\text { generated }\end{array}$ & $\begin{array}{l}\text { g CO2 eq./ } \\
\text { Sm3 } \\
\text { produced gas }\end{array}$ & $\begin{array}{c}\% \mathrm{CH} 4 \\
\text { emissions/ } \\
\mathrm{CH} 4 \\
\text { extracted }\end{array}$ \\
\hline $\begin{array}{l}\text { Exploration } \\
\text { Pre-production }\end{array}$ & 0 & 0 & 0 & 0 & 0.00 & $0.0 \%$ & $0.00(0.00)$ & $0.0 \%$ & 0 & 0 & $0.00 \%$ \\
\hline Site preparation & 0.0078 & 0.15 & 0.59 & 0.0078 & 0.15 & $0.0 \%$ & $0.42(0.59)$ & $0.0 \%$ & 1.1 & 5.1 & $0.00 \%$ \\
\hline Drilling & 0.0078 & 0.19 & 0.57 & 0.0078 & 0.19 & $0.0 \%$ & $0.43(0.57)$ & $0.0 \%$ & 1.4 & 6.4 & $0.00 \%$ \\
\hline Hydraulic fracturing & 0.1197 & 0.19 & 0.52 & 0.12 & 0.19 & $0.0 \%$ & $0.51(0.52)$ & $0.0 \%$ & 1.4 & 6.4 & $0.00 \%$ \\
\hline $\begin{array}{l}\text { Well completion } \\
\text { Extraction }\end{array}$ & 0.00 & 0.081 & 86.6 & 0 & 0.06 & $97.4 \%$ & $0.44(6.8)$ & $99.3 \%$ & 0.42 & 1.96 & $0.01 \%$ \\
\hline Normal operation & 0.1 & 3.9 & 5258.8 & 1.5 & 0.3 & $99.3 \%$ & $4.8(5259.3)$ & $99.3 \%$ & 2.1 & 9.8 & $0.05 \%$ \\
\hline Liquids unloading & 0 & 0.2 & 70.3 & 0 & 0.2 & $99.3 \%$ & $6.5(70.3)$ & $99.3 \%$ & 1.3 & 6.0 & $0.03 \%$ \\
\hline Workovers & 0.0 & 0.1 & 86.6 & 0 & 0.1 & $97.4 \%$ & $2.2(34.2)$ & $99.3 \%$ & 0.42 & 1.96 & $0.01 \%$ \\
\hline Gathering & 0.058 & 2.6 & 101.8 & 0 & 0.4 & $99.3 \%$ & $6.3(101.8)$ & $99.3 \%$ & 2.93 & 13.71 & $0.07 \%$ \\
\hline Processing & 0.86 & 4.1 & 13.6 & 0.86 & 4.1 & $18.6 \%$ & 10.5 (13.6) & $37.6 \%$ & 29.2 & 136.7 & $0.13 \%$ \\
\hline T, S \& D & 0.60 & 6.3 & 29.2 & 0.60 & 5.0 & $77.8 \%$ & $10.2(12.0)$ & $51.0 \%$ & 36.0 & 168.7 & $0.67 \%$ \\
\hline Estimated total & 0 & 13.0 & 42.0 & 3.2 & 10.6 & $53.2 \%$ & 42.4 & $69.1 \%$ & 76.2 & 356.6 & $0.97 \%$ \\
\hline
\end{tabular}


Table 4. Summary of literature emissions estimates and revised CON estimates for each supply chain stage, including LNG processes. For the revised median estimate, the proportional contribution of methane is also given. The median revised estimate is also given in three other functional units: per $\mathrm{kWh}$ of electricity generated, per $\mathrm{m}^{3}$ of gas produced from a well (at $0^{\circ} \mathrm{C}$ and $1 \mathrm{~atm}$ ) and the methane emitted as a percentage of methane extracted.

\begin{tabular}{|c|c|c|c|c|c|c|c|c|c|c|c|}
\hline \multirow[b]{2}{*}{ Supply chain stage } & \multicolumn{3}{|c|}{$\begin{array}{c}\text { Raw Literature } \\
\text { ( } \mathrm{g} \mathrm{CO}_{2} \text { eq./ } \mathrm{MJ} \mathrm{HHV} \text { ) }\end{array}$} & \multicolumn{5}{|c|}{$\begin{array}{l}\text { Constrained estimate (CON) } \\
\text { (g CO2 eq./ MJ HHV) }\end{array}$} & \multicolumn{3}{|c|}{$\begin{array}{l}\text { Median CON estimate in other functional } \\
\text { units: }\end{array}$} \\
\hline & Minimum & Median & Maximum & Minimum & & $\% \mathrm{CH} 4$ & $\begin{array}{l}\text { 95th Pe } \\
\quad \text { (maxi }\end{array}$ & tile & $\begin{array}{l}\text { g CO2 eq./ } \\
\text { kWh } \\
\text { electricity } \\
\text { generated }\end{array}$ & $\begin{array}{l}\text { g CO2 eq./ } \\
\text { Sm3 } \\
\text { produced } \\
\text { gas }\end{array}$ & $\begin{array}{c}\% \mathrm{CH} 4 \\
\text { emissions/ } \\
\text { CH4 } \\
\text { extracted }\end{array}$ \\
\hline $\begin{array}{l}\text { Exploration } \\
\text { Pre-production }\end{array}$ & 0 & 0 & 0 & 0 & 0 & $0.0 \%$ & $0(0)$ & $0.0 \%$ & 0 & 0 & $0.00 \%$ \\
\hline Site preparation & 0.0078 & 0.15 & 0.59 & 0.0090 & 0.17 & $0.0 \%$ & $0.48(0.67)$ & $0.0 \%$ & 1.2 & 5.1 & $0.00 \%$ \\
\hline Drilling & 0.0078 & 0.19 & 0.57 & 0.0090 & 0.22 & $0.0 \%$ & $0.50(0.66)$ & $0.0 \%$ & 1.6 & 6.4 & $0.00 \%$ \\
\hline Hydraulic fracturing & 0.1197 & 0.19 & 0.52 & 0.14 & 0.22 & $0.0 \%$ & $0.59(0.6)$ & $0.0 \%$ & 1.6 & 6.4 & $0.00 \%$ \\
\hline $\begin{array}{l}\text { Well completion } \\
\text { Extraction }\end{array}$ & 0.00 & 0.081 & 86.6 & 0 & 0.07 & $97.4 \%$ & $0.50(7.9)$ & $99.3 \%$ & 0.48 & 1.96 & $0.01 \%$ \\
\hline Normal operation & 0.1 & 3.9 & 5258.8 & 1.8 & 0.3 & $99.3 \%$ & $5.5(6045.2)$ & $99.3 \%$ & 2.4 & 9.8 & $0.05 \%$ \\
\hline Liquids unloading & 0 & 0.2 & 70.3 & 0 & 0.21 & $99.3 \%$ & $7.5(80.8)$ & $99.3 \%$ & 1.5 & 6.0 & $0.03 \%$ \\
\hline Workovers & 0.0 & 0.1 & 86.6 & 0 & 0.1 & $97.4 \%$ & $2.5(39.3)$ & $99.3 \%$ & 0.48 & 1.96 & $0.01 \%$ \\
\hline Gathering & 0.058 & 2.6 & 101.8 & 0 & 0.5 & $99.3 \%$ & $7.3(117)$ & $99.3 \%$ & 3.36 & 13.71 & $0.07 \%$ \\
\hline Processing & 0.86 & 4.1 & 13.6 & 0.99 & 4.7 & $18.6 \%$ & $12.1(15.6)$ & $37.6 \%$ & 33.6 & 136.7 & $0.13 \%$ \\
\hline $\mathrm{T}, \mathbf{S} \& \mathrm{D}$ & 0.60 & 6.3 & 29.2 & 0.69 & 5.7 & $77.8 \%$ & $11.8(13.8)$ & $51.0 \%$ & 41.4 & 168.7 & $0.67 \%$ \\
\hline $\begin{array}{l}\text { Estimated total (without LNG) } \\
\text { LNG }\end{array}$ & 0 & 13.0 & 42.0 & 3.7 & 12.2 & $53.2 \%$ & 48.7 & $69.1 \%$ & 87.5 & 356.6 & $0.97 \%$ \\
\hline Liquefaction & 2.8 & 6.4 & 10.5 & 2.8 & 6.4 & $15.5 \%$ & $9.0(10.5)$ & $40.6 \%$ & 46.2 & 188.1 & $0.15 \%$ \\
\hline Transport & 0.86 & 2.0 & 7.3 & 1 & 1.98 & $11.0 \%$ & $4.8(7.3)$ & $0.0 \%$ & 14.3 & 58.2 & $0.03 \%$ \\
\hline Regasification & 0.3 & 0.5 & 2.5 & 0.3 & 0.5 & $18.3 \%$ & $2.1(2.5)$ & $81.6 \%$ & 3.9 & 15.8 & $0.01 \%$ \\
\hline LNG Total & 3.9 & 8.9 & 20.3 & 4 & 8.93 & $14.6 \%$ & $15.9(20.3)$ & $33.8 \%$ & 64.3 & 262.0 & $0.20 \%$ \\
\hline Estimated total (with LNG) & 11.2 & 18.3 & 31.1 & 7.6 & 21.1 & $44.3 \%$ & 64.6 & $60.4 \%$ & 151.9 & 618.7 & $1.40 \%$ \\
\hline
\end{tabular}




\section{Methodological differences}

Much of the variation in emissions estimates arises from the use of a multitude of different estimation methods. In particular this study finds large differences due to the assumed warming impact of methane, differences between top-down and bottom-up estimates, cross-sectional versus longitudinal studies, the assumed Estimated Ultimate Recovery (EUR) of the gas well, the allocation of emissions to co-products and the assumed natural gas composition. These issues are described below and their impacts on emission estimates are discussed.

\section{The climate forcing impact of methane}

As previously stated, methane emissions have a large short-term climate forcing impact compared to carbon dioxide. The instantaneous forcing impact of methane is around 120 times that of carbon dioxide on a mass basis [98]. However, methane is short-lived in the atmosphere with an average lifespan of 12 years, after which it oxidises into carbon dioxide [104]. A carbon dioxide emission will last far longer, with $25 \%$ of an emission remaining after 1,000 years [105]. Consequently, the climate forcing impact of methane emissions changes significantly over time, but the impact of carbon dioxide is much more constant.

Typically, studies use Global Warming Potentials (GWP) [106] to compare emissions of different greenhouse gases such as methane with $\mathrm{CO}_{2}$ [107]. The GWP is defined as the average timeintegrated climate forcing impact of a pulse emission of a gas over a specific time horizon, relative to carbon dioxide. For example, the GWP of methane for a time horizon of 100 years (GWP100) is 34, meaning that a pulse emission of methane is 34 times stronger than $\mathrm{CO}_{2}$ over the 100 years on average. Note that the GWP100 does not give any information on the climate forcing of methane at the end of the 100 years, only the average impact across the 100 years. Additionally, the use of a single value to compare GHGs ignores the changing impacts over time.

The time-dependence of methane emissions on climate forcing means that the GWP values can be confusing for non- $\mathrm{CO}_{2}$ related decision making, because it does not specify the future point in time that the climate change impacts are relevant for. Whether a non- $\mathrm{CO}_{2}$ emission pulse is important depends on the intended climate stabilisation level $\left(\mathrm{W} / \mathrm{m}^{2}\right)$, the timing of that stabilisation, and the background emissions prior to and after the pulse.

Indeed, the way that GWP is used in most abatement studies does not take into account the timing of emissions at all. Typically, one metric (e.g. GWP100) is used to estimate methane emissions of a well over the lifetime of the well. However, as a well may be active and emitting for 30 years or more, this means that the time horizon is not fixed at one point in the future. For example, if a well emits within the first year of operation, say 2015, the GWP100 would consider the impact up to 2115. If the well still operates and emits at 2045, the GWP100 estimation would consider the impact up to 2145 . This appears to be inconsistent, as the time horizon considered would ideally be a fixed point in the future. A fixed point time horizon may result in significantly different global warming impact results. Using the example as above, the methane emissions during the first year would have a significantly lower impact on global warming than equivalent methane emissions during the $30^{\text {th }}$ year.

As the time of required climate stabilisation grows closer, the importance of methane mitigation grows stronger. Conversely, in 2100, an emission of methane in 2015 will be seen as relatively unimportant. There is no single correct time horizon to use, as it depends on the reasons for which the estimation is being carried out. The IPCC typically uses a 100 year time horizon (GWP100), being commensurate with the scenario timescales used in its modelling work. However, 20 year time 
horizons are also quoted, and using this time horizon in calculations can significantly alter results, often leading to significant disagreement in the literature $[2,4]$. The choice is a policy decision: are we concerned about a short-term or long-term rise in climate temperature? Many countries have committed to reducing GHG emissions by 2030 or 2050, but these are interim targets with the aim of long term decarbonisation. Alvarez et al. [2] suggest that for technological environmental analyses, it is most appropriate and transparent to plot estimated GHG emissions over different time horizons. Consideration should be given to the use of other climate metrics which provide greater transparency and accuracy [e.g. 108, 109-111].

To assess the impact of the methane warming potential on results, a sensitivity analysis was conducted. Total supply chain GHG emissions were estimated for minimum, median and $95^{\text {th }}$ percentile CON estimates for different values of methane GWP and shown in Figure 7. The effect of GWP on GHG emissions is linear and large in magnitude. The central estimate GHG emissions using a GWP100 value of 34 is $10.5 \mathrm{~g} \mathrm{CO}_{2}$ eq./ MJ HHV, whereas a GWP20 of 86 increases this estimate to $19.5 \mathrm{~g} \mathrm{CO}_{2}$ eq./ MJ HHV.

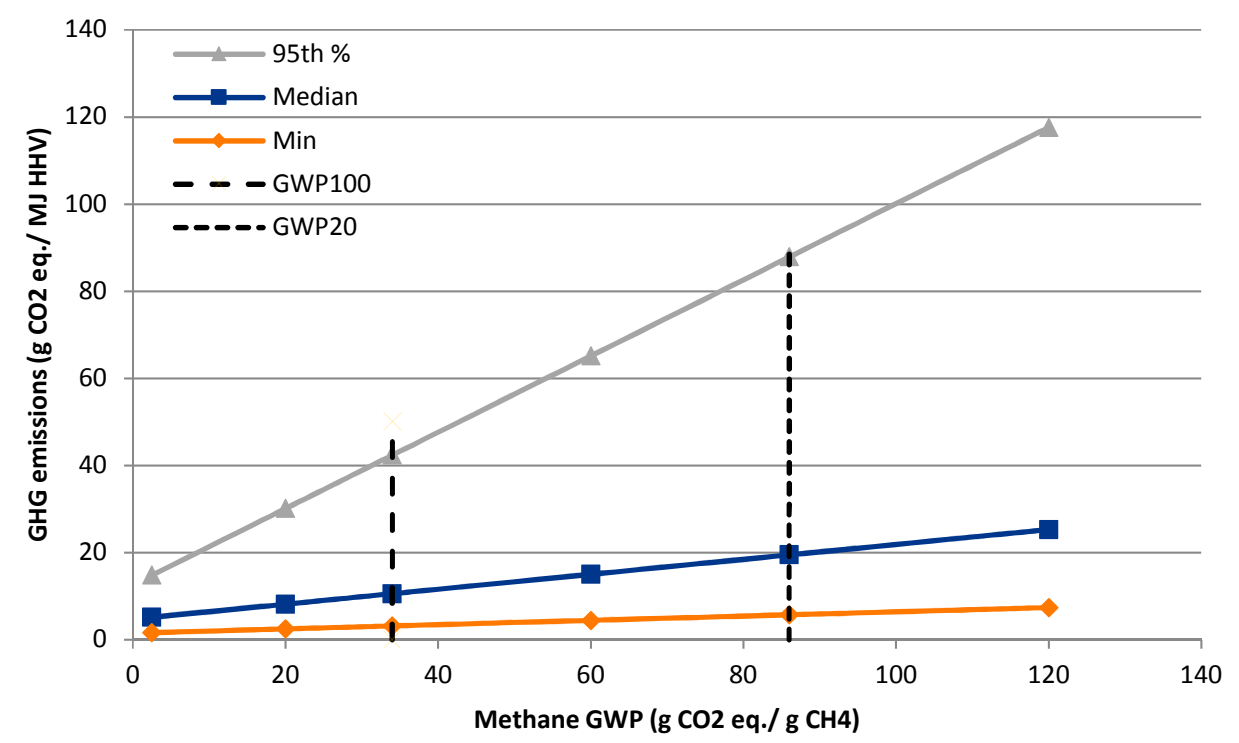

Figure 7. The impact of GWP of methane on total supply chain GHG emissions. Revised CON values of minimum, median and $95^{\text {th }}$ percentile emissions are used to demonstrate the range of expected emissions. Adapted from [11].

\section{Top-down versus bottom-up emission estimates}

Differences between top-down and bottom-up estimates appear to cause significant variation in results. Top-down methods measure atmospheric concentrations of methane from fixed ground monitors [112], mobile ground monitors [113-115], aircraft [116-118] or satellite monitoring platforms [119], and allocate the contribution made by different activities [98]. Conversely, bottomup methods measure methane emissions directly at the emission point, aggregating and extrapolating these measurements for a whole region or process [98].

Most of the top-down studies compare results to the EPA bottom-up estimates. Approximately half of the studies estimate emissions to be $1.5-2.5$ times higher than the EPA estimates $[117,118,120$ 126], whilst the other half estimate emissions to be comparable [114, 119, 122, 127-129]. However, large uncertainties associated with both estimation methods render a comparison between topdown and bottom-up estimates inconclusive $[128,129]$. Generally, bottom-up estimates may tend to underestimate emissions via either unaccounted emission sources or the presence of super emitters within the population that are not represented within the sample $[3,29,69,98,130]$. Conversely, 
top-down estimates may well overestimate emissions, due to the difficulty in allocating the atmospheric methane concentrations to specific sources [54, 98, 125, 126]. Generally, as the distance between source and measurement increases, accuracy and the ability to allocate emissions is reduced. There is a tendency to allocate measured emissions entirely to the natural gas industry as opposed to the oil industry or even livestock emissions, landfill sites or geological seepage, which could be present in the area $[131,132]$.

Whilst top down approaches often highlight high emissions that may be from the gas sector and are not accounted for in bottom up approaches [3, 98, 133], the analysis often lacks granularity. The hybridising of top-down and bottom-up approaches and the incorporation of the lower number of high emitting facilities will further improve understanding of methane emissions and their sources $[98,130]$.

\section{Cross-sectional estimates}

A large number of emissions estimates such as the top-down studies described here, are based on cross-sectional data, which are quantified over a variety of processes or a region for a fixed time period. Cross-sectional results are constrained to the point in time of analysis, where the aggregation of emissions from different wells and processes at different life cycle stages makes it difficult to transform these estimates into an estimate for the life cycle of a single well or supply route.

Conversely, longitudinal life cycle assessments of the supply chain determine all the emissions associated with a well or play or unit of production across the total life span of the supply chain. This type of analysis is imperative in order to understand the long terms impacts of energy system changes, such as a switch in technologies.

\section{Estimated ultimate recovery of wells}

One of the biggest causes of the large variation in supply chain emissions estimates is due to the assumed estimated ultimate recovery (EUR) of gas wells [16, 23, 54, 134, 135]. The EUR is the measure of economically feasible gas extraction and is dependent on the size of the well, the ease of extraction (i.e. well pressure and permeability of the formation) and the energy market, which governs the economic feasibility of production [54]. Different estimates of gas well EUR range 3 orders of magnitude, from 2 million $\mathrm{m}^{3}$ to 2,500 million $\mathrm{m}^{3}[14,16,17,19,23,28,36,48,134,136]$.

This is a vital assumption within the estimation of life cycle, longitudinal emissions, as emissions are often expressed in relation to a volume of gas produced (e.g. per $\mathrm{m}^{3}$ ) or a related functional unit (e.g. per MJ of gas content delivered). In order to determine the impact of EUR on levelised GHG estimates within this paper, the expected supply chain GHG emissions were estimated under different EUR scenarios, as shown in Figure 8. 


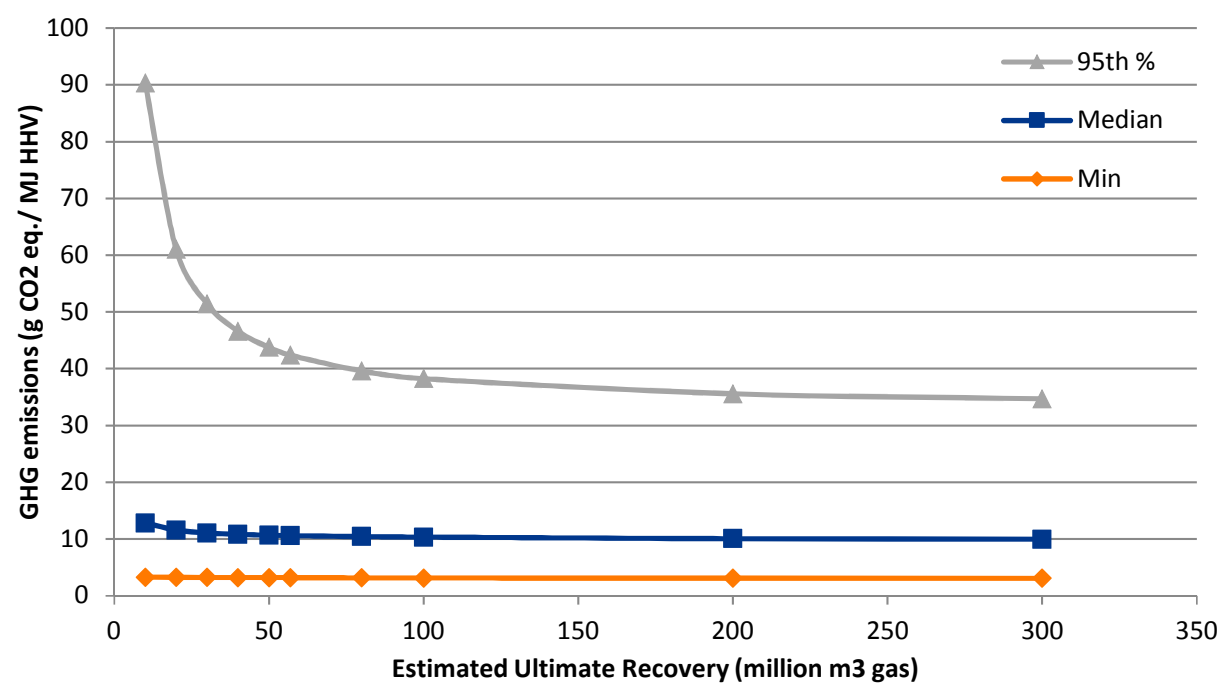

Figure 8. The impact of assume EUR on the total supply chain GHG emissions. Revised CON values of minimum, median and $95^{\text {th }}$ percentile emissions are used to demonstrate the range of expected emissions. Adapted from [11].

Whilst the minimum and median GHG estimates are not significantly affected by EUR, the high GHG estimate varies by a factor of 2 , similar to the findings of other studies [e.g. 16, 134, 137]. This effect is due to the larger contribution from 'intermittent' emissions under the high emission scenario, such as liquids unloading. Some GHG emissions are proportional to gas production (EUR), whereas others such as well completion emissions are largely independent. This means that when these independent emissions are levelised, they become inversely proportional to the EUR. The high supply chain GHG estimates have proportionally more contribution from well completions and liquids unloading, therefore they are more influenced by the assumed EUR value.

\section{Co-product allocation}

Another factor that affects the magnitude of emissions associated with the gas supply chain is the allocation of emissions to co-products. There may be a number of co-products from the natural gas supply chain, the most common being natural gas liquids (NGLs), which are heavier hydrocarbons separated at the processing stage. Total emissions are typically allocated to each product, but this creates an additional layer of uncertainty and methodological difference between studies. Life cycle assessment studies are methodologically guided by the ISO 14040/14044 guidance [138, 139], which sets out different methods of accounting for co-products. The preference is to avoid allocation by expanding the system boundary being considered, or by 'displacement' of co-products ${ }^{1}$. If this cannot be feasibly achieved, the emissions should be divided between the co-products, by economic value, mass or energy content.

The allocation method and the assumed quantity of co-product generated varies results significantly. Zavala-Araiza et al. [112] provide a good example of this: if a gas well produced $170 \mathrm{~m}^{3}$ of gas for every barrel of oil, the allocation according to energy content would be a 50:50 split (therefore one would divide the total emissions for gas by half). If the allocation was based on mass the split would be 60:40 (gas: liquid), whereas on an economic basis the split would be 19:81.

\footnotetext{
${ }^{1}$ Displacement of co-products is used when there is another 'typical' method of generating the co-product as a primary product (e.g. heavy hydrocarbons from an oil well). The method of displacement involves subtracting the avoided burden, the emissions associated with this typical process that would otherwise have been used to create the product. This is essentially crediting the natural gas life cycle chain with avoided emissions.
} 
Most studies investigated in this paper have allocated emissions based on energy content of coproducts [e.g. 23, 30, 36, 54, 112], or by mass [33]. Skone [30] and Stephenson et al. [36] allocate $88 \%$ of the extraction emissions to the natural gas product, the remainder being allocated to the heavier hydrocarbon liquids. However, the quantity of NGLs varies significantly for different wells [as seen in 44]. Furthermore, many studies do not account for co-products at all [e.g. 140]. Therefore this is a significant source of uncertainty in all estimates of gas emissions.

\section{Natural gas composition}

The composition of extracted gas may have a large impact on the supply chain emissions. This is a multifaceted issue, but impacts upon the following emissions:

- Fugitive methane emissions. A lower concentration of methane in extracted gas will reduce the quantity of fugitive methane emissions from the extraction stage

- Processing energy requirements. A higher concentration of impurities increases the energy requirements of the processing stage, thereby increasing associated emissions.

- Processing non-combusted $\mathrm{CO}_{2}$ emissions. A higher concentration of $\mathrm{CO}_{2}$ in extracted gas causes an increase in $\mathrm{CO}_{2}$ vented emissions during the processing stage where it is separated.

Therefore, a low methane concentration in the extracted gas will cause lower fugitive methane emissions, but higher processing energy requirements and more $\mathrm{CO}_{2}$ venting emissions (with a higher $\mathrm{CO}_{2}$ content). Additionally, a low methane concentration reduces the total quantity of produced gas, which would increase levelised emissions. Only one study was found that compared total supply chain emissions for varying natural gas compositions [54], suggesting a potentially significant effect but gives little granular detail. As methane has such a high GWP characterisation factor (34 for a 100 year time horizon), small changes in composition may have a large effect on GHG emissions if fugitive emissions are high.

\section{Conclusions and recommendations}

This study has aggregated the available data on methane and $\mathrm{CO}_{2}$ emissions from the natural gas supply chain and assessed in terms of the range of emissions, data availability and the different estimation methods used. The following are the key conclusions alongside a summary of further research needs, in order to improve our understanding of the role that gas could play in a lower carbon energy system.

The range of estimates of combined methane and $\mathrm{CO}_{2}$ supply chain emissions is extremely large, from 2 to $42 \mathrm{~g} \mathrm{CO}_{2}$ eq./ MJ HHV. Estimates of methane-only emissions was from $0.2 \%$ to $10 \%$ of produced gas, which is equivalent to between 1 and $58 \mathrm{~g} \mathrm{CO}_{2}$ eq./ MJ HHV. These large ranges are in part due to different natural gas extraction, processing and transport routes using different processes across different regions with varying levels of regulation.

This paper provides a constrained range of supply chain emissions that reflect the most recent measurements, resulting in a range of $3.6-42.7$ (minimum an $95^{\text {th }}$ percentile) $\mathrm{g} \mathrm{CO}$ eq./ MJ HHV with a median of $10.5 \mathrm{~g} \mathrm{CO}_{2}$ eq./ MJ HHV. The majority of emissions estimates lie at the lowest end of the scale, with a significant skew across the distribution.

There is a large body of evidence suggesting that a small number of gas extraction, processing and transmission facilities include 'super emitter' equipment. These are likely to occur via the use of ineffective process equipment and poor operational and maintenance strategies. Targeting such facilities would yield the greatest environmental improvements, but the rapid detection and elimination of these emissions potentially represents additional cost and regulation. 
The key emission sources identified within the literature are from well completions, liquids unloading, with equipment such as pneumatic devices and compressors also causing a large impact. The largest emission estimates from the literature are those with high well completion estimates for unconventional gas wells. However, the use of Reduced Emission Completions (RECs) equipment can reduce these emissions by $75-99 \%$. Estimates of liquids unloading emissions are also highly variable, but most wells do not vent at all during unloading. The distribution of unloading emissions across different regions is poorly understood and further research is required to determine this distribution and the contributing factors.

Opportunities for further reduction in supply chain emissions are in particular for fugitive emissions during extraction, transmission and distribution stages. Transmission stage methane emissions have a potentially large contribution but are highly variable across supply chains with different transmission distances. As a subject of further research, determining feasible limits for methane emission across the supply chain would contribute to understanding the emissions potential for natural gas.

A variety of methodological variations have also caused a range in emissions estimate. Many topdown methane measurement studies have been conducted in the past 3 years and are useful in validating (or otherwise) bottom-up estimates, but significant uncertainties remain. A combination of bottom-up point source measurement with local leak detection operations could help to prevent missing unknown emission sources at an appropriate level of granularity.

Assumptions regarding the warming potential of methane compared to $\mathrm{CO}_{2}$ create a large variation in emissions estimates across the literature and this study shows that increasing the GWP from 34 (100 year time horizon) to 86 (20 year) increased the revised supply chain emissions estimates by 20 $-84 \%$. Furthermore, the use of a static GWP to compare GHGs or technologies is over simplistic and does not reflect the important change in impact over time. Consideration should be given to the use of other climate metrics which provide greater transparency and accuracy [e.g. 108, 109-111].

Other methodological assumptions within emissions studies also vary significantly across the literature and can have a major effect on the estimated emissions such as the following.

- The range of estimated ultimate recovery (EUR) estimates spans 2 orders of magnitude and cause levelised GHG emissions to vary by a factor of 2 .

- The allocation of emissions to co-products such as heavier hydrocarbons has a large impact on results and many studies do not allocate at all, resulting in an overestimate of natural gas emissions.

- The composition of extracted natural gas varies significantly across the global well population and the impacts on GHG emissions are multifaceted. More research is required to determine the scale of the impact across known gas compositions.

Whilst there has been a significant drive to collect new data, there remains an unrepresentative data set for a number of key emission points over the natural gas supply chain. Methane emissions in particular are increasingly frequently being reported, not least aided by the US Greenhouse Gas Reporting Program. Specifically, more transparent data is required for regions outside of the US and specifically for offshore extraction, coal bed methane extraction, liquids unloading, well completions with RECs, transmission and distribution pipelines and all LNG stages.

A greater causal analysis of the factors affecting different supply chain emissions is required in order to understand the mitigation potential at each stage. For such a diverse range of supply chain routes, 
processes, regions and operations, it is important to understand the distribution of emissions and the causes of variation, which will require an integrated analysis from engineering, economics and political perspectives.

\section{Acknowledgements}

The Sustainable Gas Institute was founded by Imperial College London and BG Group, from which the institute gratefully receives its funding. The authors also gratefully acknowledge technical support of the expert advisory group, who assisted throughout the review process and peerreviewed the findings: David Allen (UT Austin), Adam Brandt (Stanford University), Laurence Stamford (University of Manchester), Jim Watson (UKERC, Imperial College London), Lisa Walker (BG Group) and Djamila Amimer (Shell). It should be noted that any opinions stated within this report are the opinions of the authors only.

\section{References}

1. IEA, CO2 Emissions From Fuel Combustion, in IEA Statistics. 2015, International Energy Agency: Paris. p. 152.

2. $\quad$ Alvarez, R.A., et al., Greater focus needed on methane leakage from natural gas infrastructure. Proceedings of the National Academy of Sciences of the United States of America, 2012. 109(17): p. 6435-6440.

3. Brandt, A.R., et al., Methane Leaks from North American Natural Gas Systems. Science, 2014. 343(6172): p. 733-735.

4. Howarth, R., R. Santoro, and A. Ingraffea, Methane and the greenhouse-gas footprint of natural gas from shale formations. Climatic Change, 2011. 106(4): p. 679-690.

5. Allen, D.T., et al., Measurements of methane emissions at natural gas production sites in the United States. Proceedings of the National Academy of Sciences of the United States of America, 2013. 110(44): p. 17768-17773.

6. EPA, Oil and Natural Gas Sector Hydraulically Fractured Oil Well Completions and Associated Gas during Ongoing Production, in Report for review panel, US EPA Office of Air Quality Planning and Standards, Editor. 2014, US EPA: Washington, DC.

7. Boothroyd, I.M., et al., Fugitive emissions of methane from abandoned, decommissioned oil and gas wells. Science of The Total Environment, 2016. 547: p. 461-469.

8. Kang, M., et al., Direct measurements of methane emissions from abandoned oil and gas wells in Pennsylvania. Proceedings of the National Academy of Sciences, 2014. 111(51): p. 18173-18177.

9. Townsend-Small, A., et al., Emissions of coalbed and natural gas methane from abandoned oil and gas wells in the United States. Geophysical Research Letters, 2016. 43(5): p. 22832290.

10. Vielstädte, L., et al., Quantification of methane emissions at abandoned gas wells in the Central North Sea. Marine and Petroleum Geology, 2015. 68, Part B: p. 848-860.

11. Balcombe, P., et al., Methane and $\mathrm{CO} 2$ emissions from the natural gas supply chain: an evidence assessment, Sustainable Gas Institute, Editor. 2015, Imperial College London: www.sustainablegasinstitute.org/publications/white-paper-1.

12. Jiang, M., et al., Life cycle greenhouse gas emissions of Marcellus shale gas. Environmental Research Letters, 2011. 6(3).

13. Sevenster, M. and H. Croezen, The natural gas chain: Toward a global life cycle assessment, CE, Editor. 2006, Delft. 
14. O'Donoughue, P.R., et al., Life Cycle Greenhouse Gas Emissions of Electricity Generated from Conventionally Produced Natural Gas. Journal of Industrial Ecology, 2014. 18(1): p. 125-144.

15. Shahriar, A., R. Sadiq, and S. Tesfamariam, Life cycle greenhouse gas footprint of shale gas: a probabilistic approach. Stochastic Environmental Research and Risk Assessment, 2014. 28(8): p. 2185-2204.

16. Stamford, L. and A. Azapagic, Life cycle environmental impacts of UK shale gas. Applied Energy, 2014. 134: p. 506-518.

17. Santoro, R.L., R.W. Howarth, and A.R. Ingraffea, Indirect Emissions of Carbon Dioxide from Marcellus Shale Gas Development, in A Technical Report from the Agriculture, Energy, \& Environment Program at Cornell University. 2011.

18. MacKay, D.J.C. and T.J. Stone, Potential Greenhouse Gas Emissions Associated with Shale Gas Extraction and Use. 2013, Department of Energy \& Climate Change: London.

19. Weber, C.L. and C. Clavin, Life Cycle Carbon Footprint of Shale Gas: Review of Evidence and Implications. Environmental Science \& Technology, 2012. 46(11): p. 5688-5695.

20. Bond, C., et al., Life-cycle Assessment of Greenhouse Gas Emissions from Unconventional Gas in Scotland. 2014, ClimateXchange: Edinburgh, UK. p. 94.

21. Broderick, J., et al., Shale gas: an updated assessment of environmental and climate change impacts, in $A$ report commissions by the Co-operative and undertaken by researchers at the Tyndall Centre, University of Manchester. 2011.

22. Chang, Y., et al., Shale-to-well energy use and air pollutant emissions of shale gas production in China. Applied Energy, 2014. 125: p. 147-157.

23. Heath, G., et al., Life cycle greenhouse gas emissions from Barnett Shale gas used to generate electricity. Journal of Unconventional Oil and Gas Resources, 2014. 8(0): p. 46-55.

24. EPA, Greenhouse Gas Reporting Program, United States Environmental Protection Agency, Editor. 2015: www.epa.gov/enviro/facts/ghg/customized.html.

25. Harrison, M., Revised Attachment 3: Gas Well Completion Emissions Data, URS corporation, Editor. 2012, US EPA: Austin, Texas.

26. Broomfield, M., B. Donovan, and A. Leonard, Considerations for quantifying fugitive methane releases from shale gas operations. 2014, Enviromental Agency: Bristol, UK.

27. ICF International, Economic Analysis of Methane Emission Reduction Opportunities in the U.S. Onshore Oil and Natural Gas Industries, Environmental Defense Fund, Editor. 2014: Fairfax, VA 22031.

28. Burnham, A., et al., Life-Cycle Greenhouse Gas Emissions of Shale Gas, Natural Gas, Coal, and Petroleum. Environmental Science \& Technology, 2012. 46(2): p. 619-627.

29. Shires, T. and M. Lev-On, Characterizing Pivotal Sources of Methane Emissions from Natural Gas Production, API and ANGA, Editor. 2012, URS Corporation and The LEVON Group, .

30. Skone, T.J., Life Cycle Greenhouse Gas Inventory of Natural Gas Extraction, Delivery and Electricity Production NETL, Editor. 2011, National Energy Technology Laboratory.

31. EPA, Inventory of US Greenhouse Gas Emissions and Sinks: 1990 - 2012, US Environmental Protection Agency, Editor. 2014: Washington, DC.

32. EPA, Oil and Natural Gas Sector: Standards of Performance for Crude Oil and Natural Gas Production, Transmission, and Distribution. Background Technical Support Document for Proposed Standards. 2011, US Environmental Protection Agency: Washington, DC.

33. Littlefield, J. and B.A. Hamilton, Improved Natural Gas Extraction as a Strategy for Reducing Climate Impacts of Transportation, U.D.o. Energy, Editor. 2013, National Energy Technology Laboratory: Orlando, US.

34. Norwood, P. and L. Campbell, Presentation slides: Flowback Emissions and Regulations. 2013, ERM: Oil and Gas Environmental Conference.

35. O'Sullivan, F. and S. Paltsev, Shale gas production: potential versus actual greenhouse gas emissions. Environmental Research Letters, 2012. 7(4). 
36. Stephenson, T., J.E. Valle, and X. Riera-Palou, Modeling the Relative GHG Emissions of Conventional and Shale Gas Production. Environmental Science \& Technology, 2011. 45(24): p. 10757-10764.

37. Venkatesh, A., et al., Uncertainty in Life Cycle Greenhouse Gas Emissions from United States Natural Gas End-Uses and its Effects on Policy. Environmental Science \& Technology, 2011. 45(19): p. 8182-8189.

38. EPA, Oil and natural gas sector: standards of performance for crude oil and natural gas production, transmission, and distribution. background supplemental technical support document for the final new source performance standards., United States Environmental Protection Agency, Editor. 2012: Washington DC.

39. Allen, D.T., Atmospheric Emissions and Air Quality Impacts from Natural Gas Production and Use. Annual Review of Chemical and Biomolecular Engineering, 2014. 5: p. 55-75.

40. Zammerilli, A., et al., Environmental Impacts of Unconventional Natural Gas Development and Production, National Energy Technology Laboratory, Energy Sector Planning and Analysis, and Booz Allen Hamilton, Editors. 2014, US Department of Energy (DOE): Washington, DC.

41. Omara, M., et al., Methane Emissions from Conventional and Unconventional Natural Gas Production Sites in the Marcellus Shale Basin. Environmental Science \& Technology, 2016. 50(4): p. 2099-2107.

42. Rella, C.W., et al., Measuring Emissions from Oil and Natural Gas Well Pads Using the Mobile Flux Plane Technique. Environmental Science \& Technology, 2015. 49(7): p. 4742-4748.

43. EPA, Oil and Natural Gas Sector Liquids Unloading Processes, U.S. EPA OAQPS, Editor. 2014.

44. Allen, D.T., et al., Methane Emissions from Process Equipment at Natural Gas Production Sites in the United States: Liquid Unloadings. Environmental Science \& Technology, 2014. 49(1): p. 641-648.

45. Mitchell, A.L., et al., Measurements of Methane Emissions from Natural Gas Gathering Facilities and Processing Plants: Measurement Results. Environmental Science \& Technology, 2015. 49(5): p. 3219-3227.

46. Clearstone Engineering Ltd, Identification and evaluation of opportunities to reduce methane losses at four gas processing plants, US Environmental Protection Agency, Editor. 2002, Gas Technology Institute: Calgary.

47. NGML, Cost-Effective Directed Inspection and Maintenance Control Opportunities at Five Gas Processing Plants and Upstream Gatllering Compressor Stations and Well Sites, in EPA Phase II Aggregate Site Report, National Gas Machinery Laboratory, Clearstone Engineering Ltd, and Innovative Environmental Solutions, Editors. 2006, US Environmental Protection Agency.

48. Heath, G.A., et al., Harmonization of initial estimates of shale gas life cycle greenhouse gas emissions for electric power generation. Proceedings of the National Academy of Sciences, 2014. 111(31): p. E3167-E3176.

49. Marchese, A.J., et al., Methane Emissions from United States Natural Gas Gathering and Processing. Environmental Science \& Technology, 2015.

50. Skone, T.J., et al., Life Cycle Analysis of Natural Gas Extraction and Power Generation. 2014, US Department of Energy, National Energy Technology Laboratory.

51. Weisser, D., A guide to life-cycle greenhouse gas (GHG) emissions from electric supply technologies. Energy, 2007. 32(9): p. 1543-1559.

52. Lechtenboehmer, S. and C. Dienst, Future development of the upstream greenhouse gas emissions from natural gas industry, focussing on Russian gas fields and export pipelines. Journal of Integrative Environmental Sciences, 2010. 7: p. 39-48.

53. Lechtenboehmer, S., et al., Tapping the leakages: Methane losses, mitigation options and policy issues for Russian long distance gas transmission pipelines. International Journal of Greenhouse Gas Control, 2007. 1(4): p. 387-395. 
54. Logan, J.A., et al., Natural Gas and the Transformation of the U.S. Energy Sector: Electricity, Joint Institute for Strategic Energy Analysis, et al., Editors. 2012, JISEA \& NREL.

55. Bouman, E.A., A. Ramirez, and E.G. Hertwich, Multiregional environmental comparison of fossil fuel power generation-Assessment of the contribution of fugitive emissions from conventional and unconventional fossil resources. International Journal of Greenhouse Gas Control, 2015. 33: p. 1-9.

56. Leliveld, J., et al., Greenhouse gases: Low methane leakage from gas pipelines, in Nature. 2005. p. 841-842.

57. Ishkov, A., et al. Understanding Methane Emission Sources and Viable Mitigation Measures in the Natural Gas Transmission Systems: Russian and US Experience. in International Gas Union Research Conference 2011. 2011. Seoul, South Korea.

58. Bradbury, J., et al., Clearing the air: Reducing upstream greenhouse gas emissions from US natural gas systems, in Washington, DC: World Resources Institute. 2013.

59. Hultman, N., et al., The greenhouse impact of unconventional gas for electricity generation. Environmental Research Letters, 2011. 6(4): p. 044008.

60. Lelieveld, J., et al., Greenhouse gases: Low methane leakage from gas pipelines. Nature, 2005. 434(7035): p. 841-842.

61. Kirchgessner, D.A., et al., Estimate of methane emissions from the US natural gas industry, in Chemosphere. 1997. p. 1365-1390.

62. Weisser, D., A guide to life-cycle greenhouse gas (GHG) emissions from electric supply technologies, in Energy. 2007. p. 1543-1559.

63. Ditl, P. and M. Netusil, Dehydration of Natural Gas Stored in Underground Gas Storages. Czasopismo Techniczne, Mechanika, 2012. 109(5).

64. Zimmerle, D.J., et al., Methane Emissions from the Natural Gas Transmission and Storage System in the United States. Environmental Science \& Technology, 2015. 49(15): p. 93749383.

65. Subramanian, R., et al., Methane Emissions from Natural Gas Compressor Stations in the Transmission and Storage Sector: Measurements and Comparisons with the EPA Greenhouse Gas Reporting Program Protocol. Environmental Science \& Technology, 2015. 49(5): p. 32523261.

66. Lamb, B.K., et al., Direct Measurements Show Decreasing Methane Emissions from Natural Gas Local Distribution Systems in the United States. Environmental Science \& Technology, 2015. 49(8): p. 5161-5169.

67. Moore, C.W., et al., Air Impacts of Increased Natural Gas Acquisition, Processing, and Use: A Critical Review, in Environmental Science \& Technology. 2014. p. 8349-8359.

68. Mitchell, C., METHANE EMISSIONS FROM THE COAL AND NATURAL-GAS INDUSTRIES IN THE UK, in Chemosphere. 1993. p. 441-446.

69. Harrison, M., et al., Methane Emissions from the Natural Gas Industry, Volumes 1-15. 1996, Final Report.(Gas Res Inst and Environ Protec Agency, Washington, DC) GRI-94/0257 and EPA-600/R-96-080, Appendix B-1.

70. Farrag, K., K. Wiley, and M. Harrison, Improving Methane Emission Estimates for Natural Gas Distribution Companies, Phase II - PE Pipes. Gas Technology Institute, 2013.

71. Jackson, R.B., et al., Natural Gas Pipeline Leaks Across Washington, DC. Environmental Science \& Technology, 2014. 48(3): p. 2051-2058.

72. Phillips, N.G., et al., Mapping urban pipeline leaks: Methane leaks across Boston. Environmental Pollution, 2013. 173: p. 1-4.

73. Shorter, J.H., et al., Methane emission measurements in urban areas in eastern Germany. Journal of Atmospheric Chemistry, 1996. 24(2): p. 121-140.

74. Nie, Z., A. Korre, and S. Durucan, Full Chain Analysis and Comparison of Gas-Fired Power Plants with Co2 Capture and Storage with Clean Coal Alternatives. Energy Procedia, 2013. 37(0): p. 2840-2847. 
75. Tamura, I.T., T.; Kagajo, T.; Kuwabara, S.; Yoshioka, T.; Nagata, T.; Kurahashi, K.; Ishitani, H. M. S., , Life cycle CO2 analysis of LNG and city gas. . Applied Energy 2001. 68: p. 301-319.

76. Jaramillo, P., W.M. Griffin, and H.S. Matthews, Comparative life-cycle air emissions of coal, domestic natural gas, $L N G$, and SNG for electricity generation. Environmental Science \& Technology, 2007. 41(17): p. 6290-6296.

77. Choi, W. and H.H. Song, Well-to-wheel analysis on greenhouse gas emission and energy use with natural gas in Korea. International Journal of Life Cycle Assessment, 2014. 19(4): p. 850860.

78. Okamura, T., M. Furukawa, and H. Ishitani, Future forecast for life-cycle greenhouse gas emissions of LNG and city gas 13A. Applied Energy 2007. 84: p. 1136-1149.

79. Hondo, H., Life cycle GHG emission analysis of power generation systems: Japanese case. Energy, 2005. 30(11-12): p. 2042-2056.

80. Yoon Sung Yee, Y.T., Life-cycle inventory analysis on fossil energy in Japan. Energy Economics, 1999. 25(8): p. 22-48.

81. $\mathrm{O}, \mathrm{Y} .$, A comparison of fossil energy sources from the global perspective ranging from mining to combustion. Energy Economics, 1998. 24(5).

82. Masayuki, S. and I. Atushi, Greenhouse Gas Emissions by Liquefaction and Transporation of Liquefied Natural Gas. Greenhouse Gas Control Technologies International Conference 1998, 1999.

83. Lowell, D., H. Wang, and N. Lutsey, Assessment of the fuel cycle impact of liquefied natural gas as used in international shipping, International Council on Clean Transportation, Editor. 2013, MJ Bradley and Associates \& International Council on Clean Transportation.

84. ARI and ICF, Greenhouse Gas Life-cycle Emissions Study: Fuel Life-Cycle of U.S. Natural Gas Supplies and International LNG, A.R. International and I. International, Editors. 2008, Sempra LNG.

85. Skone, T. and R. James, Role of Alternative Energy Sources. 2012.

86. Choi, W. and $\mathrm{H}$. Song, Well-to-wheel analysis on greenhouse gas emission and energy use with natural gas in Korea. The International Journal of Life Cycle Assessment, 2014. 19(4): p. 850-860.

87. Pace Global, Life Cycle Assessment of GHG Emissions from LNG and Coal Fired Generation Scenarios: Assumptions and Results Center for Liquefied Natural Gas, Editor. 2009: Fairfax, VA.

88. Walsh, C. and A. Bows, Size matters: Exploring the importance of vessel characteristics to inform estimates of shipping emissions. Applied Energy, 2012. 98(0): p. 128-137.

89. Prevention of Air Pollution from Ships, Second IMO GHG Study 2009. 2009, Marine Environment Protection Committee, International Maritime Organization

90. DECC, Guidelines to Defra/DECC's GHG conversion factors for company reporting. 2010, Department of Energy and Climate Change.

91. Dennis, S.M., Improved Estimates of Ton-Miles. Journal of Transportation and Statistics, 2005. 8(1): p. 3 pp.

92. Zavala-Araiza, D., et al., Toward a Functional Definition of Methane Super-Emitters:

Application to Natural Gas Production Sites. Environmental Science \& Technology, 2015. 49(13): p. 8167-8174.

93. ERG, City of Fort Worth Natural Gas Air Quality Study Final Report, L. Sage Environmental Consulting, Editor. 2011, City of Fort Worth: Texas, US.

94. Alvarez, R., R. Harriss, and D. Lyon, Oil and Natural Gas Sector: Liquids Unloading Processes: Attachment I, in Peer Review Responses of Environmental Defense Fund, June 16, 2014, E.D. Fund, Editor. 2014.

95. Harrison, M.R., et al., Natural Gas Industry Methane Emission Factor Improvement Study, Final Report, URS Corporation/ University of Texas at Austin, Editor. 2011: Texas. 
96. Venugopal, S., The Effective Management of Methane Emissions from Natural Gas Pipelines. 2013.

97. Allen, D.T., et al., Methane Emissions from Process Equipment at Natural Gas Production Sites in the United States: Pneumatic Controllers. Environmental Science \& Technology, 2014. 49(1): p. 633-640.

98. Allen, D.T., Methane emissions from natural gas production and use: reconciling bottom-up and top-down measurements. Current Opinion in Chemical Engineering, 2014. 5: p. 78-83.

99. EPA. Fact Sheet, Greenhouse Gases Reporting Program Implementation. November 2013; Available from: www.epa.gov/ghgreporting/documents/pdf/2009/FactSheet.pdf.

100. Prieur-Vernat, A., et al. LCA of the European gas chain: challenges and results. in International Gas Union Research Conference 2011. 2011.

101. EPA, Oil and Natural Gas Sector Completions and Associated Gas during Ongoing Production Hydraulically Fractured Oil Well Completions and Associated Gas during Ongoing Production. 2014.

102. EPA, Oil and Natural Gas Sector Compressors, in Report for Oil and Natural Gas Sector Compressors Review Panel. 2014, US EPA Office of Air Quality Planning and Standards: Washington, D.C.

103. The Prasino Group, For Determining Bleed Rates for Pneumatic Devices in British Columbia, Final Report. 2013:

http://www2.gov.bc.ca/gov/DownloadAsset?assetld=1F074ABD990D4EFB8AE555AEB3B8D7 71\&filename=prasino pneumatic ghg ef final report.pdf.

104. Myhre, G., et al., Anthropogenic and Natural Radiative Forcing., in In: Climate Change 2013: The Physical Science Basis. Contribution of Working Group I to the Fifth Assessment Report of the Intergovernmental Panel on Climate Change, T.F. Stocker, D. Qin, G.-K. Plattner, M.

Tignor, S.K. Allen, J. Boschung, A. Nauels, Y. Xia, V. Bex and P.M. Midgley (eds.), Editor. 2013, Cambridge University Press: Cambridge, United Kingdom and New York, NY, USA.

105. Joos, F., et al., Carbon dioxide and climate impulse response functions for the computation of greenhouse gas metrics: a multi-model analysis. Atmos. Chem. Phys., 2013. 13(5): p. 27932825.

106. IPCC, Climate Change: The Intergovernmental Panel on Climate Change Scientific Assessment, J.T. Houghton, G.J. Jenkins, and J.J. Ephraums (eds.), Editor. 1990: Cambridge, United Kingdom and New York, NY, USA, 364 pp.

107. Forster, P., et al., Changes in Atmospheric Constituents and in Radiative Forcing., in In: Climate Change 2007: The Physical Science Basis. Contribution of Working Group I to the Fourth Assessment Report of the Intergovernmental Panel on Climate Change, S. Solomon, D. Qin, M. Manning, Z. Chen, M. Marquis, K.B. Averyt, M.Tignor and H.L. Miller (eds.), Editor. 2007, Cambridge University Press: Cambridge, United Kingdom and New York, NY, USA.

108. Shine, K.P., et al., Alternatives to the Global Warming Potential for comparing climate impacts of emissions of greenhouse gases. Climatic Change, 2005. 68(3): p. 281-302.

109. Ekholm, T., T.J. Lindroos, and I. Savolainen, Robustness of climate metrics under climate policy ambiguity. Environmental Science \& Policy, 2013. 31: p. 44-52.

110. Huntingford, C., et al., The implications of carbon dioxide and methane exchange for the heavy mitigation RCP2.6 scenario under two metrics. Environmental Science \& Policy, 2015. 51: p. 77-87.

111. Edwards, M.R. and J.E. Trancik, Climate impacts of energy technologies depend on emissions timing. Nature Clim. Change, 2014. 4(5): p. 347-352.

112. Zavala-Araiza, D., et al., Allocating Methane Emissions to Natural Gas and Oil Production from Shale Formations. ACS Sustainable Chemistry \& Engineering, 2015.

113. Herndon, S.C., et al., Characterization of urban pollutant emission fluxes and ambient concentration distributions using a mobile laboratory with rapid response instrumentation. Faraday Discussions, 2005. 130: p. 327-339. 
114. Katzenstein, A.S., et al., Extensive regional atmospheric hydrocarbon pollution in the southwestern United States. Proceedings of the National Academy of Sciences, 2003. 100(21): p. 11975-11979.

115. Herndon, S., et al. Measuring methane emissions from industrial and waste processing sites using the dual tracer flux ratio method. in AGU Fall Meeting Abstracts. 2013.

116. Pétron, G., et al., Hydrocarbon emissions characterization in the Colorado Front Range: $A$ pilot study. Journal of Geophysical Research: Atmospheres, 2012. 117(D4): p. 2156-2202.

117. Peischl, J., et al., Quantifying sources of methane using light alkanes in the Los Angeles basin, California. Journal of Geophysical Research-Atmospheres, 2013. 118(10): p. 4974-4990.

118. Karion, A., et al., Methane emissions estimate from airborne measurements over a western United States natural gas field. Geophysical Research Letters, 2013. 40(16): p. 4393-4397.

119. Wecht, K.J., et al., Mapping of North American methane emissions with high spatial resolution by inversion of SCIAMACHY satellite data. Journal of Geophysical Research: Atmospheres, 2014. 119(12): p. 7741-7756

120. Miller, S.M., et al., Anthropogenic emissions of methane in the United States. Proceedings of the National Academy of Sciences, 2013. 110(50): p. 20018-20022.

121. Xiao, Y., et al., Global budget of ethane and regional constraints on U.S. sources. JGRD Journal of Geophysical Research: Atmospheres, 2008. 113(D21).

122. Pétron, G., et al., A new look at methane and nonmethane hydrocarbon emissions from oil and natural gas operations in the Colorado Denver-Julesburg Basin. Journal of Geophysical Research: Atmospheres, 2014. 119(11): p. 2013JD021272.

123. Wennberg, P.O., et al., On the Sources of Methane to the Los Angeles Atmosphere. Environmental Science \& Technology, 2012. 46(17): p. 9282-9289.

124. Schneising, O., et al., Remote sensing of fugitive methane emissions from oil and gas production in North American tight geologic formations. "Earth's Future, v2 n10 (October 2014): 548-558", 2014.

125. Lavoie, T.N., et al., Aircraft-Based Measurements of Point Source Methane Emissions in the Barnett Shale Basin. Environmental Science \& Technology, 2015. 49(13): p. 7904-7913.

126. Schwietzke, S., et al., Natural Gas Fugitive Emissions Rates Constrained by Global Atmospheric Methane and Ethane, in Environmental Science \& Technology. 2014. p. 77147722.

127. Kort, E.A., et al., Emissions of CH4 and N2O over the United States and Canada based on a receptor-oriented modeling framework and COBRA-NA atmospheric observations. Geophysical Research Letters, 2008. 35(18): p. L18808.

128. Hsu, Y.-K., et al., Methane emissions inventory verification in southern California. Atmospheric Environment, 2010. 44(1): p. 1-7.

129. Caulton, D.R., et al., Toward a better understanding and quantification of methane emissions from shale gas development. Proceedings of the National Academy of Sciences, 2014. 111(17): p. 6237-6242.

130. Zavala-Araiza, D., et al., Reconciling divergent estimates of oil and gas methane emissions. Proceedings of the National Academy of Sciences, 2015. 112(51): p. 15597-15602.

131. Townsend-Small, A., et al., Isotopic measurements of atmospheric methane in Los Angeles, California, USA: Influence of â€œfugitiveâ€ù fossil fuel emissions. "Journal of Geophysical Research: Atmospheres, v117 nD7 (16 April 2012)", 2012.

132. Lyon, D.R., et al., Constructing a Spatially Resolved Methane Emission Inventory for the Barnett Shale Region. Environmental Science \& Technology, 2015. 49(13): p. 8147-8157.

133. Kort, E.A., et al., Four corners: The largest US methane anomaly viewed from space. Geophysical Research Letters, 2014. 41(19): p. 6898-6903.

134. Cooper, J., L. Stamford, and A. Azapagic, Environmental Impacts of Shale Gas in the UK: Current Situation and Future Scenarios. Energy Technology, 2014. 2(12): p. 1012-1026. 
135. Dones, R., X. Zhou, and C. Tian, Life Cycle Assessment (LCA) of Chinese energy chains for Shandong electricity scenarios. International Journal of Global Energy Issues, 2004. 22(2): p. 199-224.

136. Dale, A.T., et al., Process Based Life-Cycle Assessment of Natural Gas from the Marcellus Shale. Environmental Science \& Technology, 2013. 47(10): p. 5459-5466.

137. Dones, R., T. Heck, and S. Hirschberg, Greenhouse gas emissions from energy systems: comparison and overview, Swiss Centre for Life-Cycle Inventories, Editor. 2004, Paul Scherrer Institute (PSI).

138. ISO, ISO 14040-environmental management - life cycle assessment - principles and framework. 2006: Geneva.

139. ISO, ISO 14044-environmental management - life cycle assessment - requirements and guidelines. 2006: Geneva.

140. NETL, Life Cycle Analysis: Natural Gas Combined Cycle (NGCC) Power Plant. 2010.

\section{Biographies}

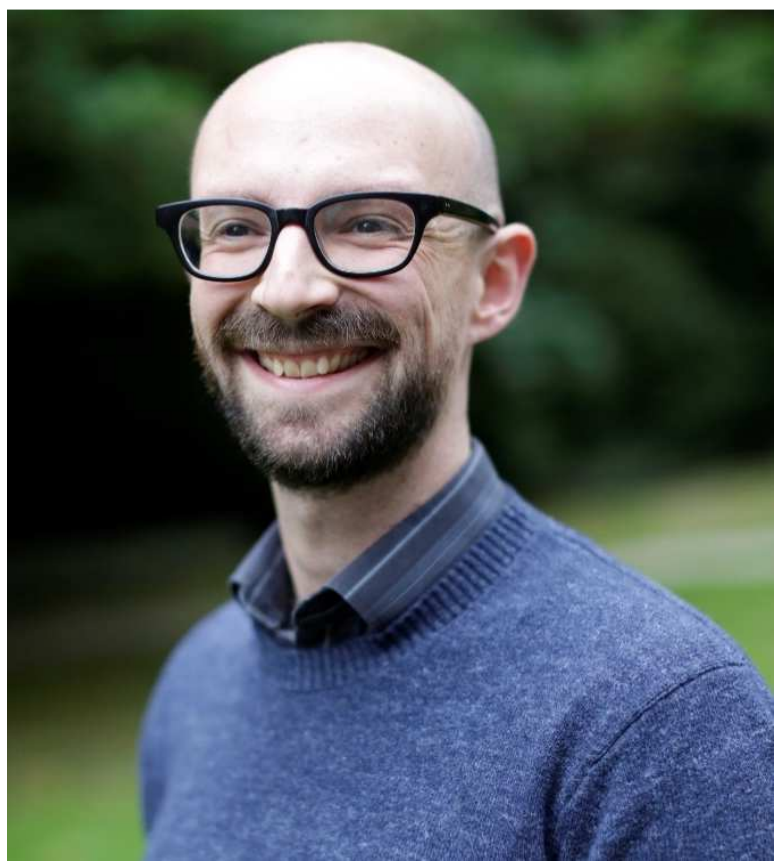

Dr Paul Balcombe, Research Associate

Paul is currently a research associate at the Sustainable Gas Institute, Imperial College London, investigating the environmental and economic impacts associated with the natural gas supply chain and determining pathways to reduce these impacts. Paul moved to the Sustainable Gas Institute from Manchester, where he achieved a first class degree in Chemical Engineering (MEng 2002 2006), attained chartered engineer status from his time in industry (2006 - 2010) and then completed his PhD (2010 - 2014). Using environmental life cycle analysis, process simulation and behavioural economic theory, his multi-disciplinary $\mathrm{PhD}$ was about how small-scale renewable energy technologies could contribute to meeting UK climate change and energy security targets. 
Paul's research interests involve the environmental, economic and technical assessments of energy industry to answer a number of key questions: how can we decarbonise our energy use whilst maintaining living standards; what role should fossil fuels have in decarbonisation targets; and how can energy policy help us to do this most effectively?

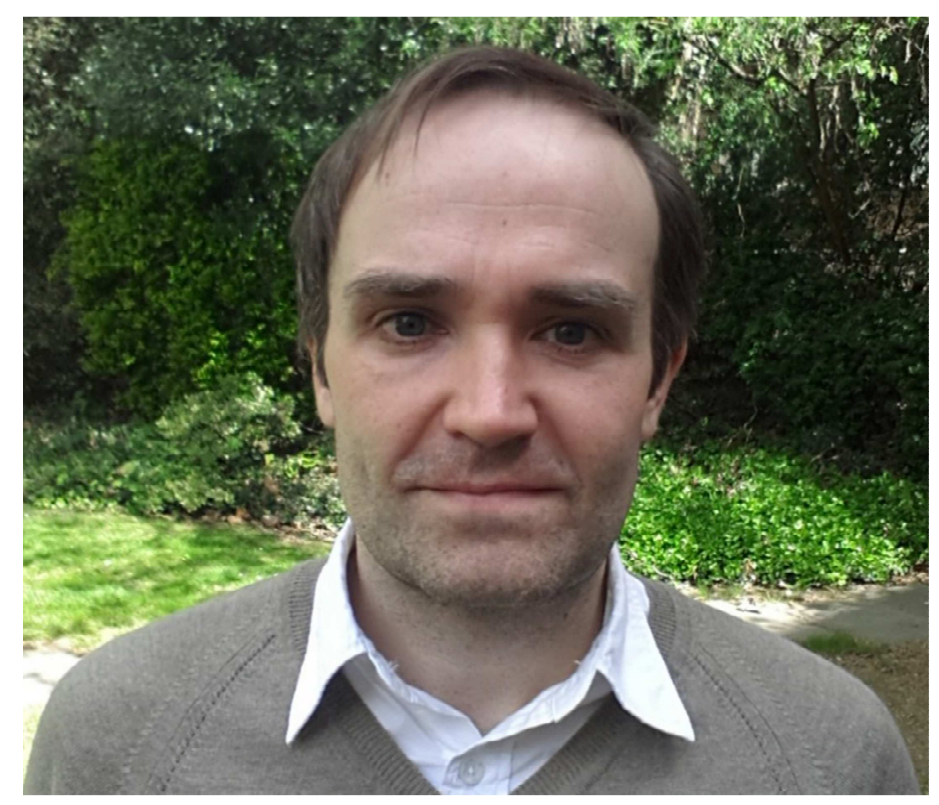

Dr Kris Anderson, Research Fellow

Kris began his oil and gas career as a core analyst at a Geoscience company in Aberdeen before completing a degree in Materials Chemistry at the University of Aberdeen and a PhD in Chemical Engineering at the Queen's University of Belfast. During his 15 year career he has carried out research for Chevron, UOP, BP, PETRONAS and Cameron. From 2010 to 2015 he worked on the commercialisation of various oil and gas technologies at PETRONAS' research centre in Kuala Lumpur, Malaysia. His main area of expertise is in the development and commercialisation of oil and gas separation technology. 


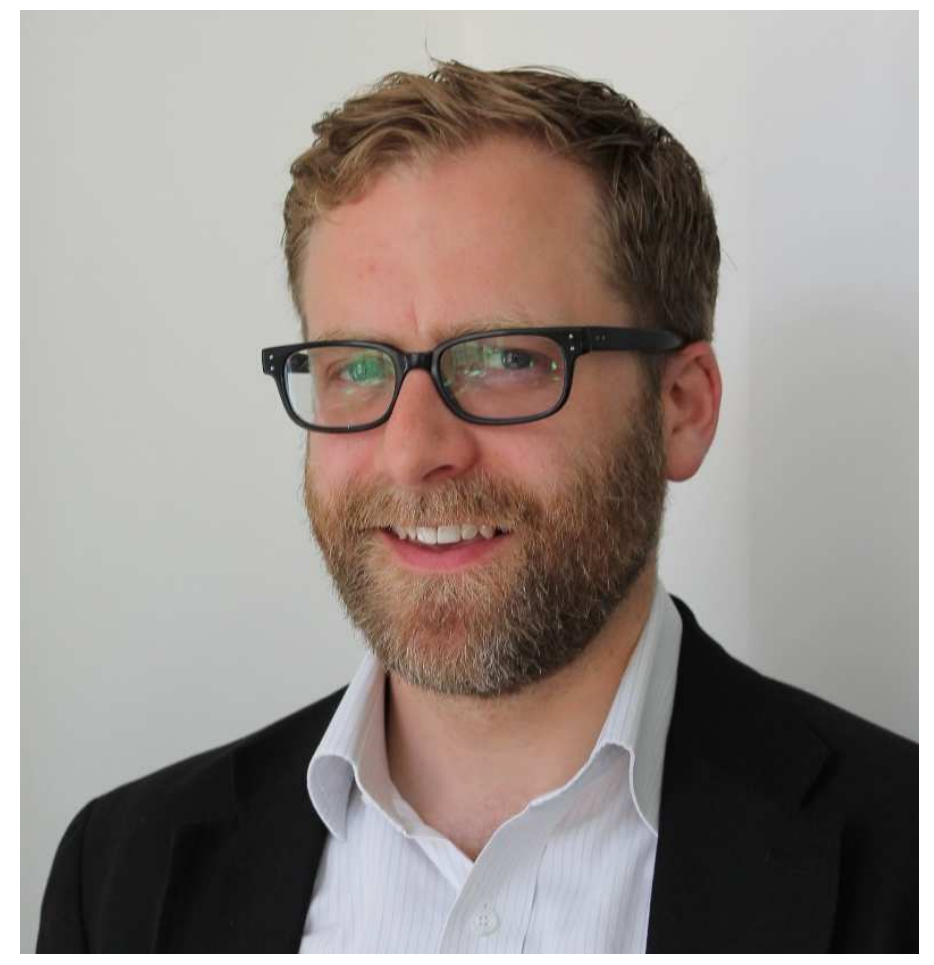

Dr Jamie Speirs, Research Fellow

Jamie is a Research Fellow in the Department of Earth Science and Engineering at Imperial College London and leads the Sustainable Gas Institute's White Paper Series. He joined Imperial College in 2007, working in the Centre for Environmental Policy, before joining SGI in March 2016.

Jamie conducts research on the social, technical and economic issues affecting energy policy in the UK, Europe and globally. For the last eight years, Jamie has conducted systematic reviews of contentious energy topics as part of the UK Energy Research Centre.

His research has examined supply of critical metals for low-carbon technology manufacturing, the macroeconomic and employment impacts of government support for renewable energy, the future for unabated coal power stations, and the resource availability of global oil and unconventional fossil fuels. 


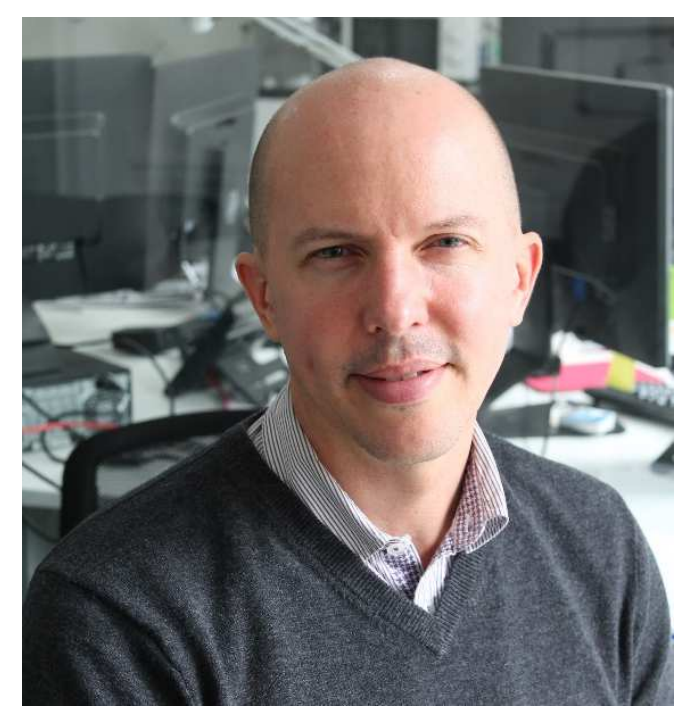

Dr Adam Hawkes, Senior Lecturer and Deputy Director of the Sustainable Gas Institute

Adam is a Senior Lecturer in Energy Systems in the Centre for Process Systems Engineering, and has extensive experience in modelling systems of energy technologies, energy and climate change consultancy, energy trading, government policy impact assessment, and ICT development.

His key research interest is the methodologies for quantitative assessment of energy systems. Building from engineering fundamentals, his team analyses the technical, economic, security, and environmental aspects of energy system transitions using innovative methods, and then applies these to provide evidence to both engineering and energy policy debates.

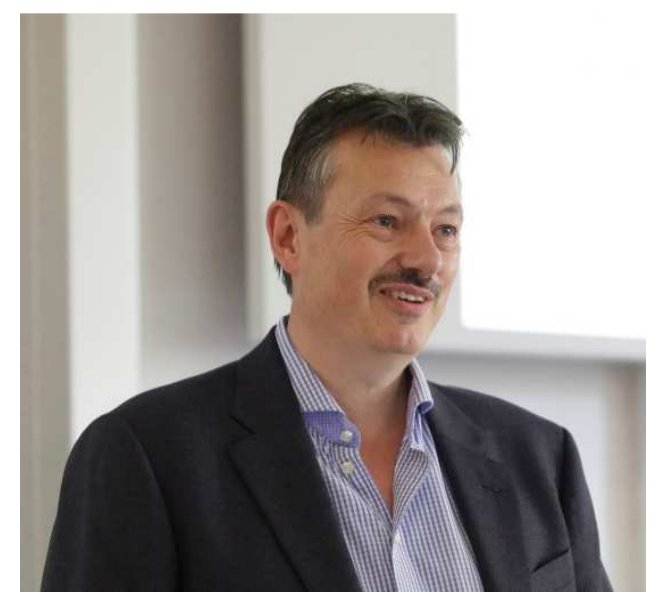

Prof Nigel Brandon OBE, FREng, Director of the Sustainable Gas Institute

Nigel Brandon was the founding Director of the Energy Futures Lab at Imperial College London and a founder of AIM listed fuel cell company, Ceres Power. His research focus is electrochemical power sources for fuel cell and energy storage applications. He has led collaborations with industry and leading research centres within this field, and is also Director of the Hydrogen and Fuel Cells SUPERGEN Hub, funded by the RC Energy programme. 


\section{Table of Contents Graphic}

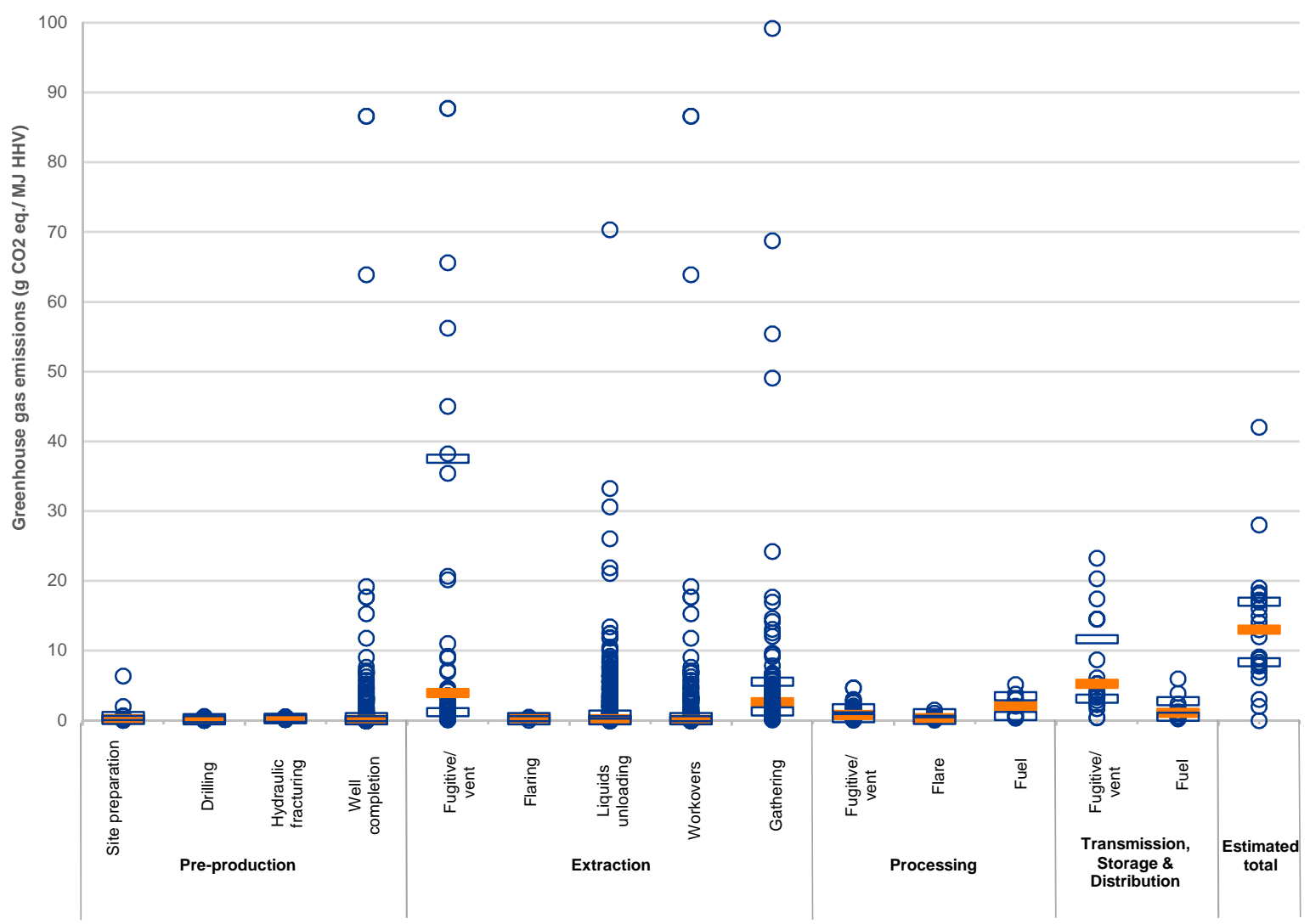

The natural gas supply chain: the importance of methane and carbon dioxide emissions

Paul Balcombe, Kris Anderson, Jamie Speirs, Nigel Brandon, Adam Hawkes

A comprehensive compilation of estimated greenhouse gas emissions across each stage of global natural gas supply chains 